\title{
Human myocyte-specific enhancer factor 2 comprises a group of tissue-restricted MADS box transcription factors
}

\author{
Yie-Teh Yu, ${ }^{1}$ Roger E. Breitbart, Leslie B. Smoot, Youngsook Lee, Vijak Mahdavi, and Bernardo \\ Nadal-Ginard \\ Howard Hughes Medical Institute and Department of Cardiology, Children's Hospital, Department of Cellular and \\ Molecular Physiology and Department of Pediatrics, Harvard Medical School, Boston, Massachusetts 02115 USA
}

\begin{abstract}
The MEF2 site is an essential element of muscle enhancers and promoters that is bound by a nuclear activity found, so far, only in muscle and required for tissue-specific transcription. We have cloned a group of transcription factors from human muscle that are responsible for this activity: They are present in muscle-specific DNA-binding complexes, have a target sequence specificity identical to that of the endogenous activity, and are MEF2 site-dependent transcriptional activators. These MEF2 proteins comprise several alternatively spliced isoforms from one gene and a related factor encoded by a second gene. All share a conserved amino-terminal DNA-binding domain that includes the MADS homology. MEF2 transcripts are ubiquitous but accumulate preferentially in skeletal muscle, heart, and brain. Specific alternatively spliced isoforms are restricted to these tissues, correlating exactly with the presence of endogenous MEF2 activity. Furthermore, MEF2 protein is detected only in skeletal and cardiac muscle nuclei and not in myoblast and nonmuscle cells. Thus, post-transcriptional regulation is important in the generation of tissue-specific MEF2 activity. Cardiac and smooth, as well as skeletal, muscles contain functionally saturating levels of MEF2 trans-activating factors that are absent in nonmuscle cells. Moreover, MEF 2 is induced in nonmuscle cells by MyoD; however, MEF2 alone is insufficient to produce the full muscle phenotype. Implications for the molecular mechanisms of myogenesis are considered.
\end{abstract}

'Key Words: MEF2; muscle-specific transcription factors; DNA-binding proteins; alternative splicing; MADS gene family]

Received March 13, 1992; revised version accepted July 7, 1992.

Significant progress has been made in understanding the mechanisms leading to the conversion of a mesenchymal precursor to a terminally differentiated skeletal muscle cell, but many of the molecular events in this developmental cascade remain to be elucidated. Moreover, despite the phenotypic similiarites among skeletal, cardiac, and, to a lesser extent, smooth muscle, the significance of the mechanisms operative in skeletal myocytes for the production of cardiac and smooth muscle phenotypes is questionable. For this reason, there has been a search, unsuccessful until now, for factors that would regulate tissue-specific gene expression in all three muscle types.

Upon growth factor removal, skeletal myoblasts form terminally differentiated myotubes with the concomitant induction of a battery of muscle-specific genes (for review, see Emerson et al. 1986). The control regions of many of these genes interact with a complex set of cell-

${ }^{1}$ Present address: Division of Cardiology, Department of Medicine, School of Medicine, Vanderbilt University, Nashville, Tennessee 372322170 USA. specific and ubiquitous factors that combinatorially produce muscle-specific transcription (Walsh and Schimmel 1987; Muscat et al. 1988; Braun et al. 1989; Buskin and Hauschka 1989; Gossett et al. 1989; Yu and Nadal-Ginard 1989; Mar and Ordahl 1990; Thompson et al. 1991; for review, see Rosenthal 1989|. To date, the best-characterized muscle-specific regulatory factors are the myogenic basic helix-loop-helix (bHLH) proteins of the MyoD family (for review, see Rosenthal 1989; Emerson 1990; Olson 1990; Weintraub et al. 1991). Muscle gene induction by these proteins depends on sequence-specific DNA binding at the E-box present in many muscle enhancers and promoters. However, not all muscle genes contain E-boxes; and even when present, they are not uniformly required for efficient muscle-specific expression (Bouvagnet et al. 1987; Walsh and Schimmel 1987; Mar and Ordahl 1990; Miller 1990; Peterson et al. 1990; Thompson et al. 1991). It is reasonable to expect that other transcription factors, regulated directly or indirectly by the MyoD family, mediate activation and highlevel expression of these genes, but these factors have not yet been identified. In addition, many genes induced 
by MyoD in skeletal muscle are also expressed in cardiac and, in some cases, smooth muscle where myogenic bHLH proteins have not been found and unrelated lineage-determining genes may operate (Davis et al. 1987; Hopwood et al. 1989; Sassoon et al. 1989; Wright et al. 1989; R.E. Breitbart, unpubl.). A plausible model for the activation of the same genes in skeletal, cardiac, and smooth muscle would invoke transcription factors common to all three lineages. Again, no such regulatory molecules have been isolated until now.

A candidate for such a factor is the myocyte-specifc enhancer-binding factor 2 (MEF2), an activity identified in skeletal muscle nuclear extracts that binds sequences in a number of muscle-specific enhancers and promoters with the consensus $(\mathrm{C} / \mathrm{T}) \mathrm{T}(\mathrm{A} / \mathrm{T})(\mathrm{A} / \mathrm{T}) \mathrm{AAATA}(\mathrm{A} / \mathrm{G})$, and is distinct from a ubiquitous binding activity (Braun et al. 1989; Gossett et al. 1989; Horlick et al. 1990; Cserjesi and Olson 1991). Deletion of MEF2-binding sites from regulatory regions of the muscle creatine kinase (MCK), cardiac myosin light chain 2 (MLC-2), and MLC $1_{\mathrm{f}} / 3_{\mathrm{f}}$ genes resulted in dramatic reduction in transcription, indicating that the MEF2 sites are required for full activity (Braun et al. 1989; Gossett et al. 1989; Wentworth et al. 1991; Zhu et al. 1991). The timing of the appearance of MEF2 DNA-binding and trans-activating function during myogenesis and in response to MyoD and myogenin suggests that this is a muscle-specific transcription factor located downstream from the MyoD family in the differentiation pathway /Gossett et al. 1989; Mueller and Wold 1989; Cserjesi and Olson 1991; Lassar et al. 1991).

We have used a consensus MEF2 DNA-binding site to screen a cDNA expression library from human skeletal muscle. In this report we present the isolation and characterization of different skeletal and cardiac cDNA clones. The corresponding mRNAs are produced by two separate genes that, through alternative splicing, encode several distinct proteins. These proteins share domains strikingly homologous to the DNA-binding and dimerization domains of the recently identified MADS gene family, named for the yeast mating-type specific transcription factor MCM1, two plant homeotic genes agamous and deficiens, and human serum response factor $\underline{S} R F$ (for review, see Schwarz-Sommer et al. 1990; Coen and Meyerowitz 1991). While this manuscript was in preparation, Pollock and Treisman (1991) reported several cDNAs based on their homology to SRF. These SRFrelated factors, isolated from nonmuscle sources, appear to be distinct alternatively spliced isoforms of the clones that we describe here. Although suspected to be a component of endogenous MEF2 activity, they were found to lack the muscle-specific DNA-binding and trans-activation functions that characterize this activity.

The cloned gene products that we describe in this report have a DNA-binding specificity indistinguishable from that of endogenous MEF2. In contrast to results with the SRF-related isoforms, antibodies raised against these proteins show them to be restricted to cell types that express MEF2 activity, and cotransfection of these cDNAs with reporter constructs containing MEF2-bind- ing sites resulted in a specfic increase in the promoter activity of these constructs in nonmuscle cells. Endogenous MEF2 DNA-binding and trans-activating activities are detected exclusively in skeletal, cardiac, and smooth muscle cells, as well as in response to MyoD in certain nonmuscle cells. Our findings indicate that post-transcriptional mechanisms, including alternative RNA splicing, are important in the tissue-specific expression of MEF2 activity. Taken together, these results define the molecular nature of MEF2 and advance our understanding of muscle-specific gene regulation.

\section{Results}

MEF2 and related isoforms are members of the MADS gene family

Using oligonucleotides containing four concatenated copies of the MCK MEF2-binding site sequence, we screened a cDNA expression library generated from primary human skeletal myocytes cultured from vastus lateralis and obtained a single positive clone producing a protein that specifically bound the probe. The $2.97-\mathrm{kb}$ insert has a long open reading frame (ORF) encoding a predicted polypeptide of 507 amino acids, provisionally named MEF2, with a calculated molecular mass of 54.8 $\mathrm{kD}$. The amino-terminal region of the encoded MEF2 protein (amino acids $3-57$ ) is closely homologous to the conserved DNA-binding and dimerization domains of the recently identified MADS gene family, comprising a series of yeast and human transcription factors and plant homeotic loci (for review, see Schwarz-Sommer et al. 1990; Coen and Meyerowitz 1991). A region rich in basic residues (amino acids 3-31) overlaps a relatively long predicted $\alpha$-helix from amino acids $23-48$. Beyond the MADS domain, there is a distinctive sequence of 27 consecutive glutamines and prolines (amino acids 420-446) and another region rich in serine and threonine (amino acids $141-186,43 \% \mathrm{~S}+\mathrm{T}$ ). Domains such as these are important for the transcription activation function of other factors (Courey and Tjian 1988; Courey et al. 1989; Mermod et al. 1989).

We also screened an adult human cardiac ventricle cDNA library using an MEF2 cDNA subfragment (nucleotides 342-728) encompassing the MADS domain as a probe. Among the 16 positives isolated were several apparently alternatively spliced isoforms of the original MEF2 clone, all products of the same gene (Fig. 1C). One partial cDNA isoform (lowercase in Fig. 1A) has an alternatively processed $5^{\prime}$-untranslated sequence that excludes the segment from nucleotides 56-262. This deleted domain is an Alu repetitive element (Jelinek and Schmid 1982). This isoform also has an additional 80 nucleotides of untranslated sequence at its $5^{\prime}$ end. A second alternative splicing event results in the substitution of translated sequences: Amino acids 87-132 (nucleotides 673-810) in the original MEF2 isoform are replaced by a different peptide, shorter by 2 codons, in the alternative isoform named aMEF2. These alternative peptide sequences share limited homology, with 15 iden- 
A MEF2

gtgtgcgcgecegecagctgctecggagat acggaattgeattttgtgaaaaagaacaa gaattttctgcaaggatcatatctaagtgcactttttgctgatacttcattcta......
GAATTTTCTGCAAGGATCATATCTAAGTGCACTTTTTGCTGATACTTCATTTCTAGACAT TGAGTCTCACTCTACCCCCAGGCTGAGTGCAGTGGTGTatCTCGGTTCACTGCAACC TCCGCCTCCAGGTTCAAGTATTCTCGTACCTCAGCCTCCCGAGTAGCTGGGATTACAGG CGCCTGCCACCATGCCTGGCTGATATTTATATTTTAGTAGAGATGGAGTTCACCATGT TGGCCAGGCTGGTCTCGAACTCTGGACCTCAGATCTTGTAGAAATTTCAGCTGTAGCCC ttggact agaagctgaaataacagaagct gtgtacgat gcatt agggt at gaagaaaat
TTGGACTAGAAGCTGAAATAACAGAAGCTGTGTACGATGCATTAGGGTATTGAAGAAAAT taacttttgaattaaatatttggaatataaggaaataaggaaagttgactgaaaatgggo cggaagaaaat acaaatcacacgcataatggat gaaaggaaccgacaggtcactttttac

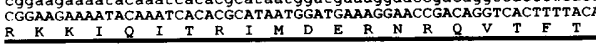
aagagaaagtt tggattaatgaagaaag

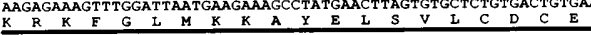
ATAGCACTCATCATTTTCAACAGCTCTAACAAACTGTTTCAATATGCTAGCACTGATAT

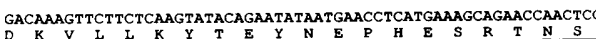

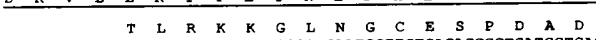
ACTTTAAGAAAGAAAGCCTTAATGGTTGTGAGAGCCCTGATGCTGA $\underset{I}{\text { GATATTGTTGAGGCTCTGAACAAGAAGGAACACAGAGGGTGCGACAGCCCAGACCCTGA }}$

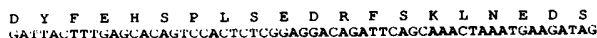
ACTTCATATTGCTAACTCACATACAGAGAAAAATATAAAAAAATTAATGAGGAATT
$T$ S Y V L T

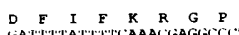

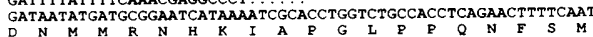
TCTGTCACAGTTCCAGTGACCAGCCCCAATGCTTTGTCCTACACTAACCCAGGGAGTTC

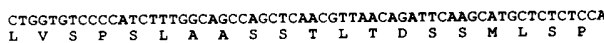

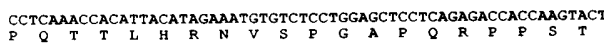
GGCAATGCAGGTGGGATGTTGACCACTACAGACCTCACAGTGCCAAATGGAGCTGGAAGC AGTCCAGTGGGGAATGGATTTGTAAACTCAAGAGCTTCTCCAAATTTGATTGGAGCTACT GGTGCAAATAGCTTAGGCAAAGTCATGCCTACAAAGTCTCCCCCTCCACCAGGTGGTGG

B

CGGAGCCGGAGATGCAGCTCAAGGGGAaGAAAGCGCCGTGAaGAACCTGGTGGACAGCAG CGTCTACTTCCGCAGCGTGGAGGGTCTGCTCAAACAGGCCATCAGCATCCGGGACCATAT GAATGCCAGTGCCCAGGGCCACAGCCCGGAGGAACCACCCCCGCCCTCCTCAGCCTGATC CTGGAAGAGACTCGGGGCCCCCCAGCCTCCGCCAACCCAGACAAAGATCATTCCACTCAG CCTGGGACGATGGGGAGGAAAAAAATCCAGATCTCCCGCATCCTGGACCAAAGGAATCGG

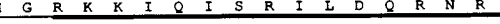

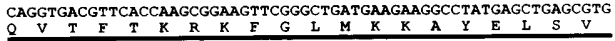

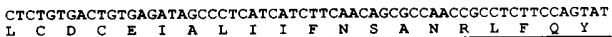

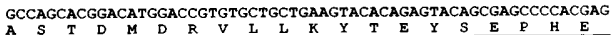
AGCCGCACCAACACTGACATCCTCGAGACGCTGAAGCGGAGGGGCATTGGCCTCGATGGG

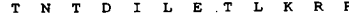
CCAGAGCTGGAGCCGGATGAAGGGCCTGAGGAGCCAGGAGAGAAGTTTCGGAGGCTGGCA GGCGAAGGGGGTGATCCGGCCTTGCCCCGACCCCGGCTGTATCCTGCAGCTCCTGCTATC CCCAGCCCAGATGTGGTATACGGGGCCTTACCGCCACCAGGCTGTGACCCCAGTGGGCTT

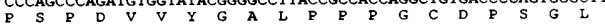
$\underset{G}{\text { GGGGAAGCACTGCCCGCCCAGAGCCGCCCATCTCCCTTCCGACCAGCAGCCCCCAAAGCC }}$ GGGCCCCCAGGCCTGGTGCACCCTCTCTTCTCACCAAGCCACCTCACCAGCAAGACACCA CCCCCACTGTACCTGCCGACGGAAGGGCGGAGGTCAGACCTGCCTGGTGGCCTGGCTGGC

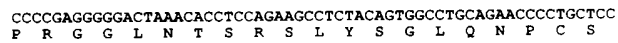
ACTGCAACTCCCGGACCCCCACTGGGGAGCTRCCCCTTCCTCCCCGGAGGCCCCCCAGTG GGGGCCGAAGCCTGGGCGAGGAGGGTCCCCCAACCCCGCGGCGCCTCCCCCGCCGACCCCCC CAGTCAGCATCAAGTCTGAGCGCCTCTCTCCGGCCCCCGGGGGCCCCGGCGACTTTCCTA AGACCTTCCCCTATCCCTTGCTCCTCGCCCGGTCCCTGGCAGAGCCTCTGCGGCCTGGGC CCGCCCTGCGCCGGCTGCCCTTGGCCGACGGCTGGCCCCGGTAGGAGATCACCCGGTGGC
$P$ ACCAGCCCAGAGCGCTCGCCAGGTACGGCGAGGGCACGTGGGGACCCCACCTCCCTCCAC
$T$ S GCCTCTTCAGAGAAGACCCAACAGTGACGCCCCCCTCCGCGGTGGGGGCTTGGAGGTGGO CGGCTGGACTCAATCCACCCTGGGGGGCTCCTTTCCTTCTTCCTATTTGTGTGTATATCC ACA $\overline{\overline{A T A A A A}} \mathrm{CGCGCGTGGCGTCCGTGGACCAGAAAAAAAAAAAAAAAAAAAAAAAAAAA}$

C 120 180 240 360 420
57 480
77 540
97 600
117 660 720
157 780
177 840
197 900 960 1020
257

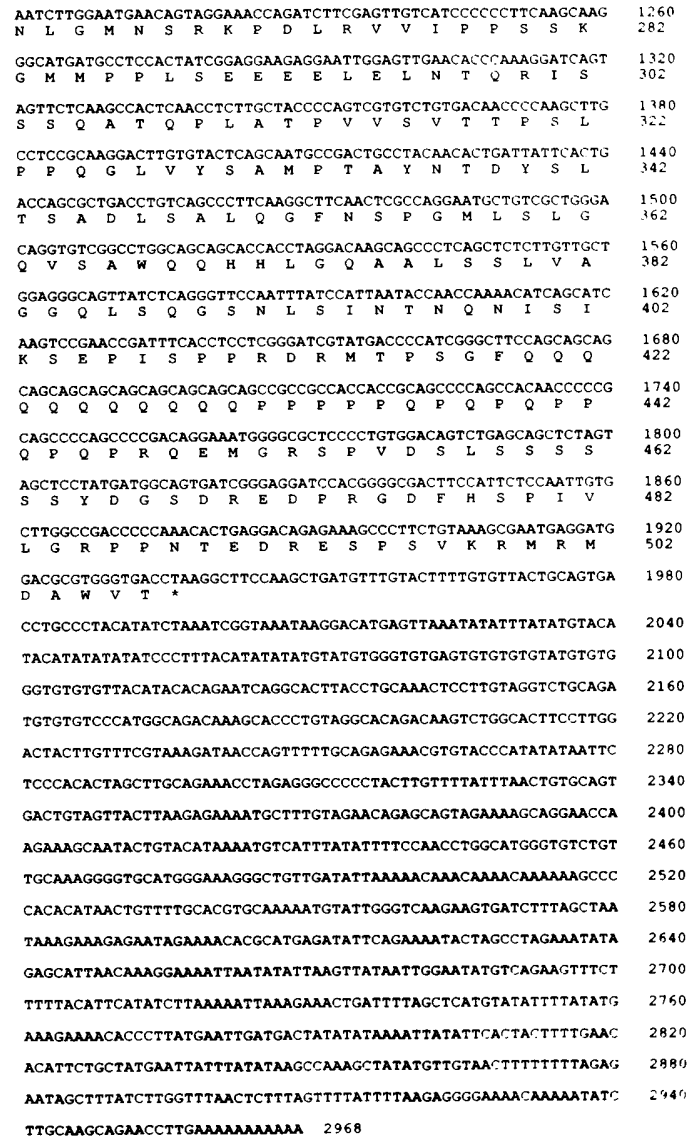

\section{MEF2 - Related Gene Products}

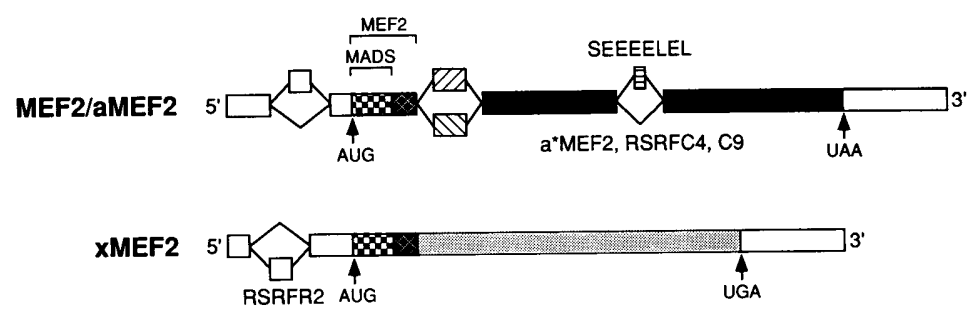

Figure 1. MEF2 alternatively spliced isoforms and xMEF2 are members of the MADS gene family. (A) The nucleotide (1-2968) and predicted amino acid (1-507) sequences of the MEF2 cDNA are shown in uppercase letters. The aMEF2 cDNA differs from MEF2 in the alternatively spliced exon beginning at nucleotide 673 (amino acids 87), which is 2 codons shorter and is indicated above the MEF2 sequence. The underlined region is highly conserved between MEF2 isoforms and xMEF2 (see $B$ ), and includes the MADS domain underlined in bold. The sequence of the clone containing the alternatively spliced $5^{\prime}$-untranslated region is indicated in lowercase letters (unnumbered), with the dotted line overlying the excluded Alu repeat. $(B)$ The nucleotide $(1-1500)$ and predicted amino acid (1-365) sequences of the XMEF2 CDNA are shown. The conserved underlined region corresponds to that in $A$. The remainder of the sequence is entirely divergent. The canonical polyadenylation signal is overlined. (Note that nucleotide 1 is actually from the linker used in cloning.| $|C|$ Diagram of the various alternatively spliced MEF2 and XMEF2 gene products. Regions: (Open) Untranslated sequence; (checkered) MADS domain; (crosshatched) MEF2 conserved regions; (hatched) MEF2 and aMEF2 alternative coding exons. The alternative sequence encoding the peptide SEEEELEL, absent in RSRFC4/RSRFC9 (Pollack and Treisman 1991), is indicated by horizontal stripes. 
tical residues and 12 conservative substitutions out of 44 positions.

MEF2 and aMEF2 are isoforms of the same gene that also encodes the human SRF-related clones RSRFC4 and RSRFC9 (Pollock and Treisman 1991), as is clear from the extensive sequence identity and genomic structure (R. Waldmann; Y.-T. Yu et al.; both unpubl.). RSRFC4 and RSRFC9 lack the 5'-untranslated Alu sequence present in one of our isolates. In addition, nucleotides 1279-1302 in Figure 1, encoding amino acids SEEEELEL (residues 289-296 in MEF2), are absent from RSRFC4/ RSRFC9, presumably as a result of alternative RNA splicing (see also below). Also absent are 2 of the 11 glutamine codons (CAG) at nucleotides 1672-1704, possibly owing to alternative splicing also, most likely at adjacent splice acceptor sites (CAGCAGCAG). Furthermore, the RSRFC4/RSRFC9 sequence lacks a single A nucleotide among the three at nucleotides 1892-1894, possibly a sequencing discrepancy, which produces a shifted reading frame with a different carboxyl terminus 11 amino acids shorter than MEF2. Other minor differences in RSRFC4/RSRFC9, either allelic or sequencing discrepancies that do not affect the protein sequence, include the absence of two GT repeats at nucleotides 2084-2093 and two $G \rightarrow T$ transversions at nucleotides 1767 and 2655.

We also isolated the product of a second related gene by low-stringency screening of the human cardiac library (Fig. 1B). This 1.5-kb cDNA, named xMEF2, has a 365amino-acid-long ORF following the methionine codon at nucleotide 250 . The predicted protein has a calculated molecular mass of $38.6 \mathrm{kD}$. Residues $3-57$ constitute a MADS domain identical to MEF2 at 50 of 55 positions. The XMEF2 and MEF2 peptide sequences remain similar immediately downstream of this domain over another 29 residues, with just four conservative substitutions. The corresponding nucleotide sequences are $76 \%$ homologous over these regions. Beyond residue $86, \mathrm{MEF} 2$ and xMEF2 have no substantial similarity. This point of divergence aligns precisely with the beginning of the MEF2/aMEF2 alternative peptides (see Fig. 1C), consistent with it being an exon boundary. The remainder of xMEF2 is peculiarly proline rich $(22 \%)$ overall; however, it lacks a long glutamine/proline domain like that found in MEF2. Of note, however, xMEF2 is an alternatively spliced isoform of the gene that also encodes the SRFrelated clone RSRFR2 (Pollock and Treisman 1991): The protein sequences are identical, but at nucleotide $33 / 34$ xMEF2 lacks 178 nucleotides of $5^{\prime}$-untranslated sequence containing the sole upstream in-frame stop codon present in RSRFR2.

\section{Cloned and endogenous MEF2 have identical DNA-binding specificities}

We undertook experiments to compare the DNA-binding specificity of cloned proteins with that of the endogenous muscle activity. Electrophoretic mobility shift assay (EMSA) confirmed specific binding of the MCK MEF2 site in C2C12 myotube nuclear extract (Fig. 2A; probe and competitor oligonucleotide sequences are shown in Table 1), as demonstrated by others (Gossett et al. 1989). The MEF2 site probe was bound (B) by an activity in this extract (lane 2). This interaction was competed by excess unlabeled probe (lane 3) but not by the mutated MEF2 site (lanes 4,5), confirming that the interaction is specific. The A/Temb site, a cis element in the embryonic myosin heavy chain ( $\mathrm{MHCemb}$ ) promoter important for its muscle-specific activity (Bouvagnet et al. 1987; Y.-T. Yu and B. Nadal-Ginard, in prep.), was a less effective competitor (lanes 6,7). Unrelated A/T-rich sequences including CArG, which is a target for another MADS protein SRF (Boxer et al. 1989), and the OTF-2 site (Scheidereit et al. 1987) did not compete at all for MEF2-binding (lanes 8-11); nor did the MEF2 oligonucleotide compete for CArG binding in complementary experiments (lanes 13-15), consistent with previous reports (Gossett et al. 1989). Furthermore, the extract bound MEF2 mutant site mt4, but not mt6, distinguishing between ubiquitous and muscle-specific binding (lanes 16-18), as shown previously (Cserjesi and Olson 1991). These data confirm that the MEF2 site is specifically bound by a myotube nuclear factor distinct from known ubiquitous binding activities.

Cloned MEF2 exhibited the same DNA-binding specificity as the endogenous myotube activity in similar EMSAs which CDNA-encoded, in vitro-translated MEF2 (Fig. 2B). The mobility of the complex formed by this protein with the MEF2 probe was identical to that in the myotube extract (cf. lanes 4 and 2). Competition for this binding by the same series of oligonucleotides used in Figure $2 \mathrm{~A}$ showed that the relative affinity of the cloned MEF2 for these sites exactly recapitulates that of the endogenous activity (lanes 5-10). In vitro-translated MEF2 bound mt4, but not mt6, again identical to the endogenous muscle-specific binding activity (lanes 1113). The same binding specificity was also reproduced by in vitro-translated aMEF2, the alternative isoform /data not shown|. Thus, these cloned factors have a DNAbinding specificity indistinguishable from that of endogenous muscle MEF2.

\section{MEF2 and aMEF2, but not XMEF2, bind multiple cardiac and skeletal muscle gene promoter elements in vitro}

The promoters or enhancers of many muscle-specific genes contain essential A/T-rich elements that conform fully or partially to the MEF2 site consensus (Cserjesi and Olson 1991). We used oligonucleotide probes corresponding to these sequences in EMSAs to determine the relative affinities of in vitro-translated MEF2-related isoforms (Table 1). Both MEF2 and aMEF2 bound all the sites listed in decreasing order of affinity in Table 1. Remarkably, the cardiac MLC- 2 HF- 1 and $\alpha-M C H ~ A / T-1$ sites have identical core sequences (TTAAAAATAA); however, the former was bound avidly while the latter was bound poorly, implicating the flanking sequences in site specification.

In every instance, aMEF2 bound severalfold more ef- 

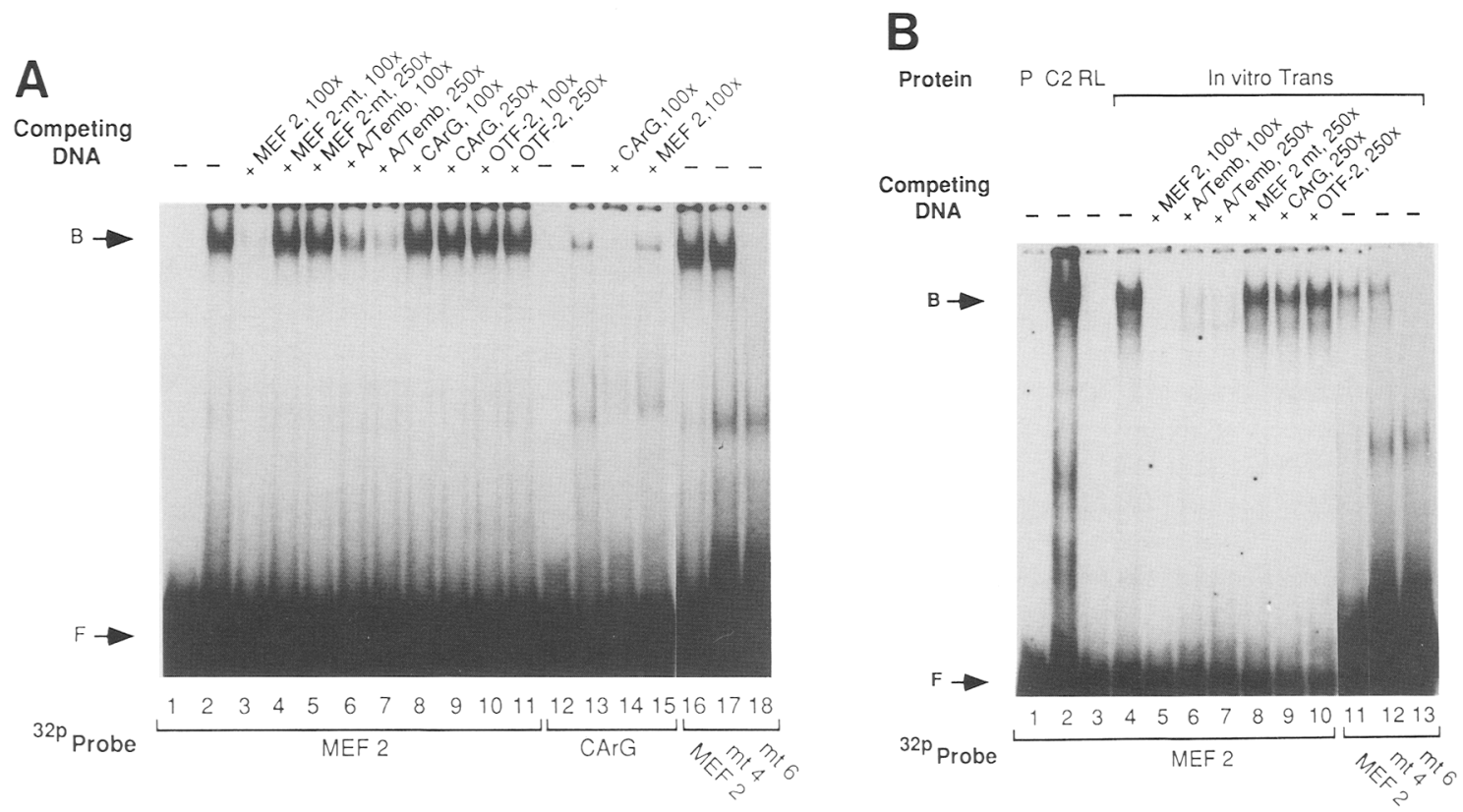

Figure 2. Endogenous myotube MEF2 and cloned MEF2 have identical DNA-binding specificities. $(A) \mathrm{C} 2 \mathrm{C} 12$ myotube nuclear extract was assayed for binding to the radiolabeled MEF2, CArG, and MEF2 mutant probes (specified at bottom) in the absence ( - ) or presence $(+)$ of a 100 - or 250-fold molar excess of unlabeled competing oligonucleotide (specified at top|, with sequences shown in Table 1. Bound probe (B) was separated from free (F) by EMSA and detected by autoradiography. Lanes 1 and 12 show probe without extract. $(B)$ In vitro-translated MEF2 protein from the cloned MEF2 cDNA was assayed simlilarly for DNA binding. Controls showing probe alone $(\mathrm{P})$, bound in myotube nuclear extract $(\mathrm{C} 2)$, and not bound in unprogrammed rabbit reticulocyte lysate (RL) are included for comparison (lanes 1-3).

fectively than MEF2 (not shown); thus, the alternative peptides, which lie well outside of the shared MADS domain, must modulate the binding properties of these proteins. Progressive carboxy-terminal deletion of cloned MEF2 translated in vitro and assayed in EMSA demonstrated that as many as 46 additional residues carboxy-terminal to the MADS homology region are re- quired for DNA-binding (data not shown). The alternatively spliced isoform of aMEF2 lacking the SEEEELEL peptide (termed a ${ }^{*}$ MEF2, corresponding to RSRFC9) showed binding indistinguishable from aMEF2 (data not shown). XMEF2, with a nearly identical MADS domain, bound none of these sequences when in vitro-translated or assayed in nuclear extracts of XMEF2-transfected COS

Table 1. Nucleotide sequences of probes and competitor DNAs used in MEF2-binding assays

\begin{tabular}{lrc}
\hline $\begin{array}{l}\text { Probe/competitor } \\
\text { DNA }\end{array}$ & Sequence & MEF2 \\
binding
\end{tabular}

Only the core sequences of the double-stranded oligonucleotides are shown. $1+$ and -1 Positive and negative binding of the probes, respectively. Nucleotides in bold print conform to the consensus sequence of the MEF2 site as reported by Cserjesi and Olson (1991). 
Yu et al.

cells (data not shown). Its homolog RSFR2 also failed to bind DNA in vitro (Pollock and Treisman 1991). Whether or not XMEF2 has distinct target sequences is currently under investigation.

Skeletal-as well as cardiac-and smooth muscle-specific DNA-binding activity is due to $M E F 2$ / $a M E F 2$

To investigate the tissue-specificity of the MEF2 protein isoforms, we compared nuclear extracts from a variety of cell types in EMSAs with the MCK MEF2 probe (Fig. 3A). The differentiation of skeletal myoblasts to myotubes in both $\mathrm{C} 2 \mathrm{C} 12$ (lanes 2,3) and Sol8 (lanes 5,6) cells was accompanied by a marked increase in binding. Similarly, NIH-3T3 fibroblasts normally devoid of this activity developed MEF2-binding upon transient transfection with MyoD (lanes 8,9). These data are consistent with previous work documenting the induction of this activity during myogenesis and in response to myogenin (Gossett et al. 1989; Cserjesi and Olson 1991). It is striking that smooth muscle cells and primary cardiocytes, which lack known myogenic bHLH factors, also contained specific MEF2-binding activity (lanes 4,7). In contrast, cells outside of these muscle lineages showed only a slower migrating complex $(\mathrm{H})$ distinct from the muscle-specific complex (C3H10T1/2 fibroblasts and HeLa cells, lanes 10,11; see also below).

Tissue-specific expression of MEF2 isoforms was dem- onstrated further by use of polyclonal antisera to define the proteins in MEF2 DNA-binding complexes (Fig. 3B). Anti-MEF2 recognizes both MEF2 and aMEF2, whereas anti-aMEF2 is specific for aMEF2 (see Materials and methods). Both antibodies produced a supershift of bound probe, confirming the presence of these factors in C2C12 myotube (lanes 2-8), cardiocyte (lanes 16-18), and smooth muscle cell (not shown) extracts, whereas preimmune and unrelated controls had no effect. In contrast, the slower migrating $\mathrm{H}$ complex lacks these MEF2 proteins and was not supershifted in HeLa (lanes 9-13), COS (lanes 14,15), and liver (lanes 19-21) extracts nor in C3H10T1/2 or CACO (colon carcinoma) cells (data not shown|, confirming that ubiquitous binding of the probe is not the result of the cloned factors. A fraction of the $\mathrm{H}$ complex from liver extract seems to be supershifted; whether a small amount of MEF2 is expressed in liver tissue or possibly arises from vascular smooth muscle in the organ remains to be determined.

Thus, MEF2 DNA-binding activity is restricted to the skeletal, cardiac, and smooth muscle lineages. The antibody supershifts demonstrate unambiguously that tissue-specific MEF2 DNA-binding activity is directly attributable to the cloned MEF2 gene products. It is particularly interesting here that anti-aMEF2, which is specific for only one (aMEF2) of the alternative isoforms, supershifted virtually all of the bound probe in these assays. Either these complexes comprise aMEF2 alone, or MEF2 : aMEF2 heterodimers that are shifted intact by this antibody.
A
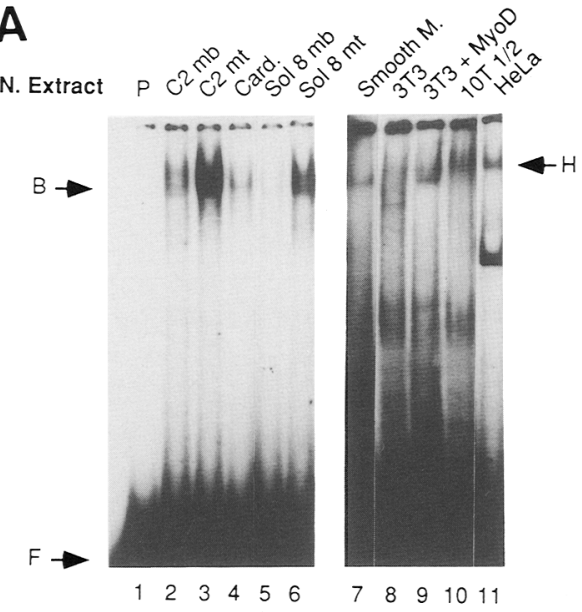

B

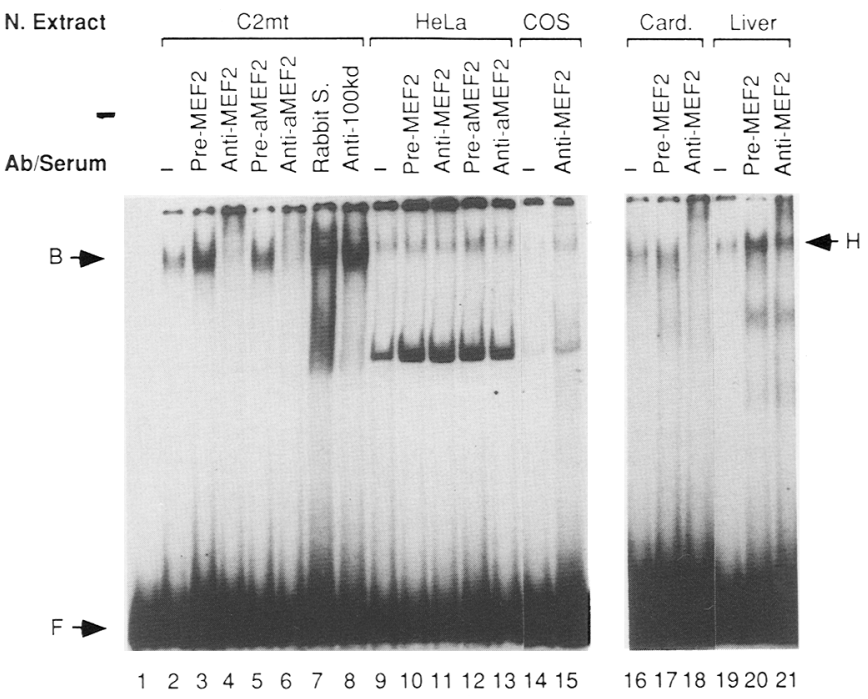

Figure 3. Skeletal-, cardiac-, and smooth muscle-specific DNA-binding activity is the result of MEF2/aMEF2. (A) Nuclear extracts from $\mathrm{C} 2 \mathrm{C} 12(\mathrm{C} 2)$ and Sol8 myoblasts $(\mathrm{mb})$ and myotubes $(\mathrm{mt})$, rat primary cardiocytes (Card), rat pulmonary artery smooth muscle cells (Smooth M), C3H10T1/2 fibroblasts (10T1/2), HeLa cells, and NIH-3T3 cells untransfected (3T3) or transiently transfected with MyoD $(3 \mathrm{~T} 3+\mathrm{MyoD})$ were used in EMSAs in which free MEF2 probe $(\mathrm{F})$ was separated from specifically bound probe $(\mathrm{B})$ or from the nonmuscle complex $(\mathrm{H})$, which migrated more slowly (lower band in HeLa is a nonspecific artifact). (B) Specific MEF2 DNA-binding activity is recognized by anti- MEF2 antibodies. Immune sera included anti-MEF2, specific for MEF2 and aMEF2, and anti-aMEF2, specific for aMEF2. Controls included the corresponding preimmune sera (Pre-MEF2, Pre-aMEF2) or unrelated antisera (Rabbit S, Anti-100kd). Extracts specified in $A$ were also used here, in addition to those of COS cells and rat liver tissue. 
Cloned factors are MEF2 site-dependent transcriptional activators

A considerable body of data show that the MEF2 site is critical for tissue-specific transcription conferred by muscle gene promoters and enhancers (Braun et al. 1989; Gossett et al. 1989; Wentworth et al. 1991; Zhu et al. 1991). Our results to this point correlate tissue-specific binding at the MEF2 site with the cloned gene products. To determine whether these proteins are functional transcription factors, we examined their capacity to transactivate promoters containing MEF2 sites.
MEF2 cDNAs, subcloned into the pMT2 eukaryotic expression vector, were cotransfected with various reporter plasmids in nonmuscle cells. As diagramed in Figure $4 \mathrm{~A}$, the reporter constructs comprise the bacterial chloramphenicol acetyltransferase (CAT) gene linked either to the basal MHCemb promoter (Bouvagnet et al. 1987; Yu and Nadal-Ginard 1989| or to the heterologous herpes simplex virus (HSV) thymidine kinase (TK) promoter (McKnight and Kingsbury 1982). Each promoter was tested with or without two copies of intact or mutated MEF2-binding sites (Fig. 4B). Parallel experiments in HeLa (Fig. 4A), CV-1, NIH-3T3, and C3H10T1/2 (not
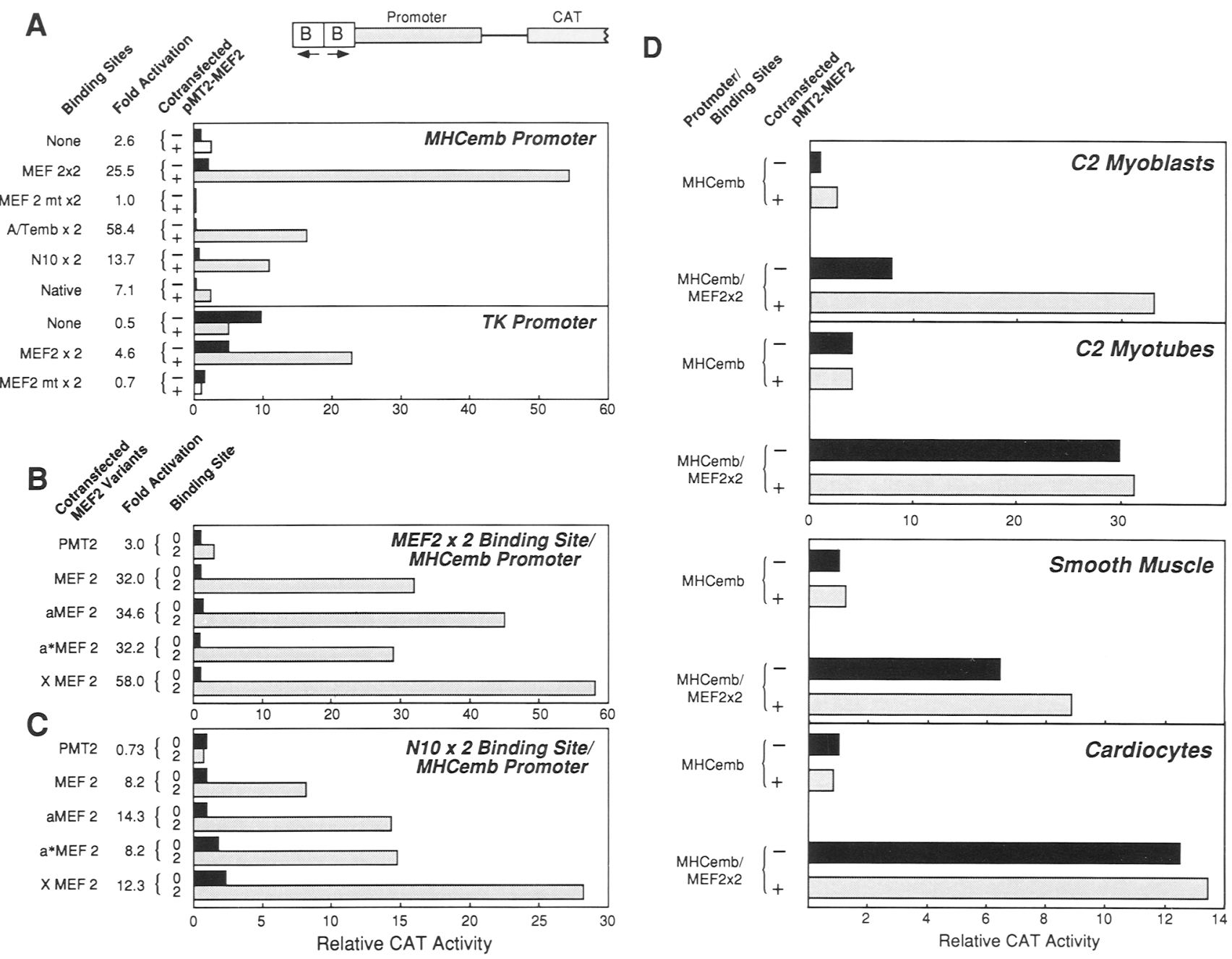

Figure 4. Cloned MEF2 reproduces site-dependent transcriptional activation present in skeletal, cardiac, and smooth muscle. A prototype of the various CAT reporter genes is diagramed. The promoters and duplicated binding sites $(\mathrm{B}$, with arrows indicating antiparallel orientation) are those specified in each of the panels that follow. $(A-C)$ CAT activity produced in HeLa cells by cotransfection of the MEF2 cDNA expression construct pMT2-MEF2 $1+1$ or pMT2 control DNA $1-1$, and of the basal MHCemb or the HSV TK promoters linked to a series of intact or mutated duplicated binding sites: (None) No binding sites; (MEF2 $\times 2$ ) MCK MEF2 sites; $($ MEF2mt $\times 2$ ) mutated MCK MEF2 sites; (A/Temb $\times 2$ ) MHCemb MEF2 sites; (N10 $\times 2$ ) N10WT (Pollock and Treisman 1991); and (Native) MHCemb native promoter $(-175$ to +1$)$, containing its single A/T-rich MEF2 site. $(B)$ Activation of the basal MHCemb promoter, with no (0) or duplicated (2) MCK MEF2 sites, in response to the indicated cotransfected MEF2 cDNA expression constructs (pMT2 is the empty expression vector), as detailed in the text. $(C)$ The analogous series of cotransfections was carried out with the MCK MEF2 sites replaced with N10. (D) The expression of the indicated reporter genes in C2C12 myoblasts and myotubes, rat primary cardiocytes, and rat pulmonary arterial smooth muscle cells cotransfected with $(+)$ and without $(-)$ the MEF2 cDNA expression construct. 
shown) cells all gave similar results. The MEF2 expression vector pMT2-MEF2 produced marked transcriptional activation of reporters containing the MCK MEF2binding site $(\mathrm{MEF} 2 \times 2)$ or the related $\mathrm{A} / \mathrm{Temb}$ site from the $\mathrm{MHCemb}$ promoter $(\mathrm{A} / \mathrm{Temb} \times 2)$. Control experiments with reporter constructs containing MEF2 site mutants (MEF2mt $\times 2$ ) or no MEF2-binding sites (none) showed that trans-activation by MEF2 depends absolutely on the presence of intact binding sites. The enhanced responsiveness of the MHCemb promoter over the TK promoter suggests that MEF2 may interact synergistically with other transcription factors that bind the MHCemb promoter. Previous results have shown that duplicated MEF2-binding sites are more effective than a single site (Gossett et al. 1989). The cloned MEF2 factors, however, can also activate the native sequences of the full MHCemb promoter $(-175$ to +1$)$ containing the single endogenous A/Temb site $(-162$ to -150 ; Y.-T. $\mathrm{Yu}$ and B. Nadal-Ginard, in prep.). This native reporter construct responds as well as that comprising two MCK MEF2 sites on the heterologous TK promoter.

We also compared the trans-activation capacities of the different MEF2 isoforms (Fig. 4B). Each of the cloned factors produced substantial up- egulation, and there was no significant difference in potency among them in multiple assays. Included here is the a MEF2 variant of aMEF2 that lacks the SEEEELEL peptide (residues 289296 in Fig. 1A), corresponding to RSRFC9, which was reported not to trans-activate (Pollock and Treisman 1991). In addition, parallel experiments with the $\mathrm{N} 10 \times 2$ binding site/MHCemb promoter reporter construct, in which duplicated N10 A/T-rich binding sites (Pollock and Treisman 1991) replace the MCK MEF2 sites, showed the N10 sequence to mediate activation by all of the same isoforms (Fig. 4C). xMEF2, which gave no detectable DNA-binding in vitro, also produced trans-activation in these experiments. We infer either that XMEF2 binds DNA in vivo as a heteromeric complex with other unidentified MEF2-related isoforms or unrelated factors or it potentiates other transcription factors without contacting the DNA itself.

Together, these results document that the cloned MEF2 proteins by themselves are sufficient to produce both specific DNA-binding and trans-activation in nonmuscle cells. Therefore, the cloned sequences encode the endogenous factors responsible for MEF2 activity in vivo.

Skeletal, cardiac, and smooth muscle cells contain saturating levels of endogenous MEF2

trans-activating factors

The presence of trans-activating MEF2 activity in skeletal myotubes is well established (Gossett et al. 1989). Here, we have found that specific MEF2 DNA-binding activity is not only present in skeletal muscle, but also in cardiac and smooth muscle cells, raising the question as to whether all three muscle lineages express endogenous MEF2 transcriptional activity. To investigate this, we performed a series of cotransfection experiments in all three muscle cell types (Fig. 4D). Again, the MHCemb promoter without MEF2-binding sites was inactive. Undifferentiated $\mathrm{C} 2 \mathrm{C} 12$ myoblasts behaved much as nonmuscle cells (described above; Fig. 4A) in that transcription of the MEF $2 \times 2 / M H C e m b$ promoter was increased significantly when cotransfected with pMT2-MEF2. In fused myotubes, however, this reporter construct was already fully active without cotransfection, and there was no appreciable further stimulation when pMT2MEF2 was added. As shown, the results in primary cardiocytes and pulmonary arterial smooth muscle cells were the same as those in skeletal myotubes, that is, these cell types, in contrast to nonmuscle cells, already contain saturating levels of MEF2 activity, presumably from endogenous MEF2 itself and/or its related isoforms.

There is, therefore, an exact correlation between the tissue-specific MEF2 DNA-binding activity demonstrated in skeletal, cardiac, and smooth muscle (see Fig. 3), and functional trans-activation in these same cell types. Particularly striking is the presence of MEF2 activity in all three muscle lineages. Despite certain phenotypic similarities between smooth and striated muscle tissues, common mechanisms for specific gene regulation in these tissue types have not been described previously.

MyoD and myogenin have the well-documented capacity to produce myogenic conversion and to induce MEF2 DNA-binding activity in transfected fibroblasts (see Fig. 3A; Weintraub et al. 1989; Cserjesi and Olson 1991). MEF2 trans-activation function was also induced by MyoD in transiently transfected NIH-3T3 cells; however, in both transient and stable transfection of C3H10T1/2 fibroblats, ectopic expression of MEF2 alone failed to induce the muscle phenotype (data not shown).

\section{MEF2-related transcripts accumulate preferentially in muscle and brain tissues}

To establish a correlation between the tissue-specificity exhibited by the MEF2 isoforms in DNA-binding and trans-activation and the tissue distribution of the corresponding transcripts, we probed blots of poly $(A)^{+}$RNAs from a series of cell lines and human tissues with a MEF2 cDNA fragment (nucelotides 342-728) containing the MADS sequence (Fig. 5A,B). Surprisingly, MEF2 transcripts were found in all cells and tissues examined but were more abundant in myotubes, skeletal muscle, heart, and brain. In all samples, the predominant species is $\sim 6.5 \mathrm{~kb}$, with a minor band at $\sim 3.5 \mathrm{~kb}$. The abundance of the longer transcript is increased relative to the shorter one in differentiated myotubes, as compared with myoblasts and nonmuscle cells. Smaller bands were also detected in nonmuscle cells. Because of the possibility that the conserved MADS sequence was cross-hybridizing with transcripts from related genes (see Figs. 1 and 6), we probed the same blots with a second fragment (nucleotides 2158-2968) comprising only the MEF2 3'-untranslated sequence (Fig. 5C,D). This probe showed the same distribution of $6.5-$ and $3.5-\mathrm{kb}$ 


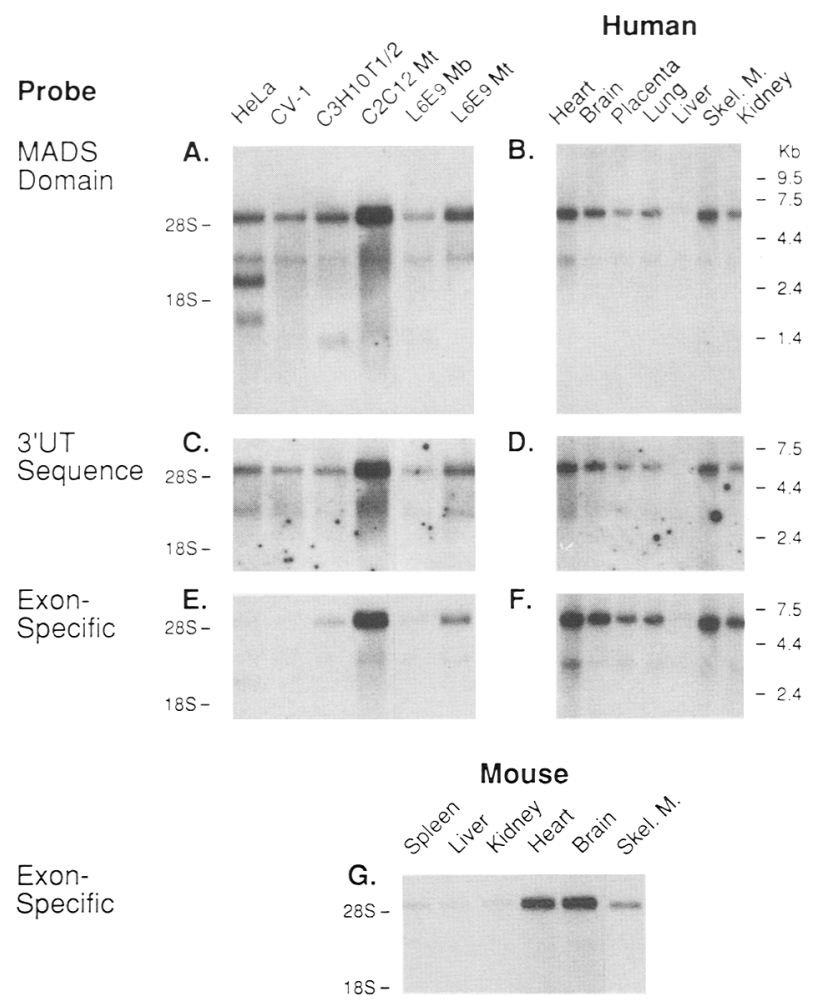

Figure 5. Ubiquitousiy expressed MEF2-related RNAs accumulate preferentially in skeletal muscle, heart, and brain. Northern blots of poly $(\mathrm{A})^{+}$RNAs from a variety of muscle and nonmuscle cell lines $[(A, C, E)(\mathrm{Mb})$ myoblasts; $(\mathrm{Mt})$ myotubes, $28 \mathrm{~S}$ and $18 \mathrm{~S}$ rRNA positions are shown] and adult human tissues $[(B, D, F)$ RNA size markers are indicated in kb] were sequentially hybridized, stripped, and rehybridized at high stringency to a series of radiolabeled probes derived from the MEF2 cDNA, including MADS domain $(A, B$; nucleotides $342-728)$ 3 '-untranslated (UT) sequence $(C, D$; nucleotides 2158-2969), and exon-specific $(E, F$; nucleotides 673-804). Another blot of adult mouse tissue poly $(\mathrm{A})^{+}$RNAs was also probed with the exon-specific probe $(G)$. The corresponding aMEF2 exon-specific probe gave identical results (not shown). Each blot has equivalent amounts of RNA per lane (see Materials and methods)

transcripts (but not the smaller bands), confirming that these species are, products of this MEF2 gene.

We hybridized the same mRNA blots to exon-specific probes complementary to the MEF2-specific (Fig. 5E,F) and aMEF2-specific (not shown) alternative sequences. Both exon-specific probes gave identical results, similar to those above, showing that transcripts containing these exons are expressed ubiquitously; but the up-regulation in differentiated myotubes was more pronounced. Thus, neither of these exons is strictly tissuespecific. Interestingly, rodent tissue RNAs, as compared with human, showed even more pronounced brain, heart, and muscle-specific expression of these sequences (Fig. 5G).

Similar Northern blot analysis for XMEF2, with a probe from this cDNA (nucleotides 1-502) that contains its MADS sequence, demonstrated that expression of the
XMEF2 gene is clearly tissue specific (Fig. 6). Again, transcripts are abundant in myotubes, skeletal muscle, heart, and brain. The major species in myotubes form a doublet at $\sim 7.5$ and $\sim 6.5 \mathrm{~kb}$, with a less abundant transcript at $\sim 3.5 \mathrm{~kb}$. In the tissues, only the $7.5-\mathrm{kb}$ and $3.5-\mathrm{kb}$ bands are seen. These XMEF2 transcripts are present at a lower level in myoblasts (which generally include a small subpopulation of differentiated myocytes in culture) and are barely detectable in nonmuscle and non-neural cells and tissues. Smaller species in HeLa and CV-1 are distinct from those seen with the corresponding MEF2 probe.

The alternatively spliced MEF2 sequence encoding the peptide SEEEELEL is specific to skeletal muscle, heart, and brain

The ubiquitous presence of MEF2-related transcripts contrasts sharply with the well-established tissue-specificity of MEF2 activity (Figs. 2-4; see Gossett et al. 1989; Cserjesi and Olson 1991). Although the mutually exclusive alternative sequences that distinguish MEF2 and aMEF2 showed no evidence of tissue-specific splicing, we investigated whether the alternative sequence encoding SEEEELEL (residues 289-296 in MEF2), present in the muscle MEF2 clones but not the nonmuscle RSRFC4 and RSRFC9 clones (Pollock and Treisman 1991), might be spliced in concordance with endogenous MEF2 activity. Using oligodeoxynucleotide primers corresponding to common regions flanking this alternative sequence (see Materials and methods), we amplified MEF2 RNA sequences from a variety of human tissues and analyzed them by Southern blotting, first using a probe hybridizing to the flanking common region (Fig. 7A). Remarkably, a 222-nucleotide product, corresponding in size to that predicted from MEF2 including SEEEELEL, was detected only in skeletal and cardiac muscle and brain. This was confirmed by reprobing the same blot with a second probe specific for this sequence (Fig. 7B). A smaller 198-nucleotide product, that is, exactly 8 codons shorter, was detected in all tissues and cells examined

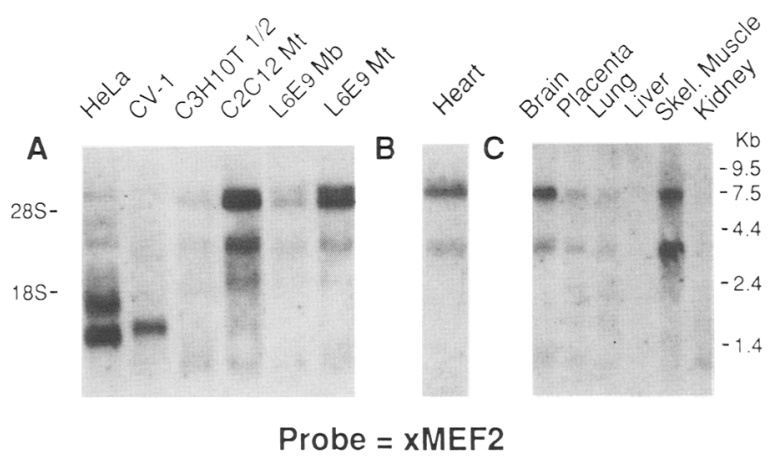

Figure 6. $x M E F 2$ RNAs are highly restricted to skeletal muscle, heart, and brain. The same cell $(A)$ and human tissue $(C)$ RNA blots shown in Fig. 5 and another of rat heart poly $(\mathrm{A})^{+}$ RNA $(B)$ were probed at high stringency with a radiolabeled fragment of the xMEF2 cDNA (nucleotides 1-502). 


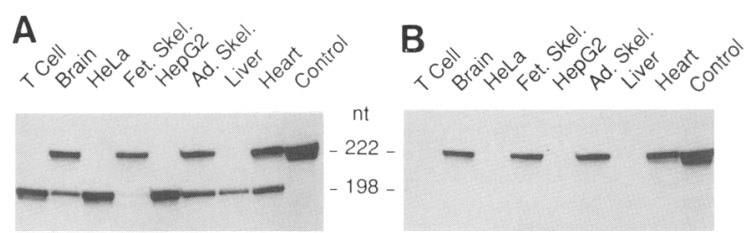

Figure 7. Skeletal muscle-, heart-, and brain-specific expression of an alternatively spliced MEF2 sequence. Reverse-transcribed MEF2 RNAs from a variety of human cell types, including Jurkat $\mathrm{T}$ cells, HeLa, HepG2 hepatoma cells, fetal brain, fetal (Fet) and adult (Ad) skeletal muscle (Skel), adult liver, and adult heart, were PCR amplified with primers flanking the sequence encoding the SEEEELEL peptide, Southern blotted, probed with radiolabeled oligodeoxynucleotides hybridizing either to the common $(A)$ or exon-specific $(B)$ sequences, and detected by autoradiography (see Materials and methods). PCR products corresponding to inclusion (222 nucleotides) or exclusion (198 nucleotides) of the alternative sequence differ by precisely the length of that sequence (24 nucleotides). (Control) The PCR product obtained by amplification of the MEF2 CDNA template. The pattern of bands in $A$ is identical to that seen on ethidium bromide staining of the original gel prior to transfer (not shown). Prolonged exposure revealed faint 222 nucleotide bands in HeLa, HepG2, and T-cell lines and liver at an intensity several hundred-fold less than that of the other bands (not shown!.

but only by the common probe. Sequencing confirmed that this species corresponds to the RSRF isoforms lacking this apparent exon (not shown). We conclude that mRNA isoforms of this gene containing the SEEEELEL sequence are highly tissue-specific and, moreover, are expressed exclusively in those cell types that have endogenous MEF2 DNA-binding and trans-activation activity (see Figs. 2-4 and below). Such strict regulation strongly suggests that this peptide participates in MEF2 tissue-specificity.

\section{$M E F 2$ protein is restricted to cells that exhibit MEF2 DNA binding and trans-activation}

To determine whether the cell-type distribution of MEF2 protein correlates with the tissue-specific MEF2 activity or the ubiquitous MEF2 mRNAs, we performed indirect immunocytofluorescence analysis using polyclonal antiMEF2 antiserum that specifically recognized both MEF2 and aMEF2 (Fig. 8A-F; see Fig. 9 and Materials and methods). MEF2 protein was detected in the nuclei of only those cell types that express MEF2 DNA-binding and trans-activation functions, including $\mathrm{C} 2 \mathrm{Cl} 2$ myotubes (Fig. 8G-I), primary rat cardiocytes (J-L), and Sol8 myotubes (not shown), coinciding with the presence of striated cytoplasmic MHC in these cells. In contrast, MEF2 protein was not detected in undifferentiated myoblasts or cardiac fibroblasts (myosin-negative cells in $\mathrm{G}-\mathrm{L}$ ), nor in a variety of nonmuscle cell lines $(M-R)$, all of which lack functional MEF2 activity.

We also found the direct correlation between endogenous MEF2 activity and the presence of MEF2 protein in immunoprecipitation experiments using the same antibodies to detect MEF2 synthesized de novo during a 3-hr $\left[{ }^{35} \mathrm{~S} \mid\right.$ methionine labeling (Fig. 9). Here, MEF2 protein comigrating with that produced in MEF2-transfected COS cells (lane 3) and by in vitro translation (not shown) was detected in amounts that increased progressively with skeletal myotube maturation (lanes 7-12), paralleling the increasing MEF2 DNA-binding activity in these cells (Gossett et al. 1989; J. McDermott; Y.-T. Yu et al.; both unpubl.). The cluster of several bands at $\sim 67 \mathrm{kD}$ indicates antibody recognition of multiple MEF2 isoforms or post-translationally modified proteins, for example, by phosphorylation. In undifferentiated myoblasts and a variety of nonmuscle cells, in contrast, no MEF2 was detected; the background signal in these cells was not competed by the addition of the specific peptide antigen (lanes 1,2,5,6,12-15). Western blot analysis with our anti-MEF2 antibodies has not been successful.

Taken together, these results demonstrate a clear concordance between high-level MEF2 protein expression and the differentiated skeletal and cardiac muscle phenotypes. Although the immunocytofluorescence data reflect the steady state of MEF2 protein synthesis and degradation, immunoprecipitation of MEF2 produced de novo in these cells during a $3 \mathrm{hr}$ labeling can be taken to indicate a cell-specific increase in MEF2 translation, unless the protein has a very short half-life. These findings confirm that MEF2 protein is present in only those cell types expressing endogenous MEF2 DNA-binding and trans-activation activities.

\section{Discussion}

In this study we have identified and characterized a family of transcription factors that exhibit all of the functions attributed to MEF2. This muscle-specific activity binds conserved promoter and enhancer elements shown to be essential for the specific transcriptional up-regulation of muscle genes (Gossett et al. 1989; Cserjesi and Olson 1991|. Several lines of evidence indicate that cDNA clones described here code for the muscle-specific MEF2 and not for ubiquitous binding activities. First, there is an absolute correlation at the cellular level between the presence of MEF2 protein and the expression of functional MEF2 DNA-binding and trans-activation. There is also an absolute correlation between these same MEF2 activities and incorporation of the alternatively spliced exon encoding SEEEELEL. The cDNA-encoded, in vitro-translated MEF2 protein and the endogenous myotube MEF2 have identical DNA-binding properties, both in terms of the mobility of their complexes in EMSA and their target sequence specificity. Both bind the mutated MEF2 site mt4, but not mt6, shown previously to differentiate between bona fide MEF2 and the ubiquitous nonspecific binding activity (Cserjesi and Olson 1991). Furthermore, antibodies raised against isoform-specific sequences in the cloned proteins recognized only the MEF2/aMEF protein-DNA complexes characteristic of muscle nuclear extracts and not those produced by any other cell type tested. Finally, forced 


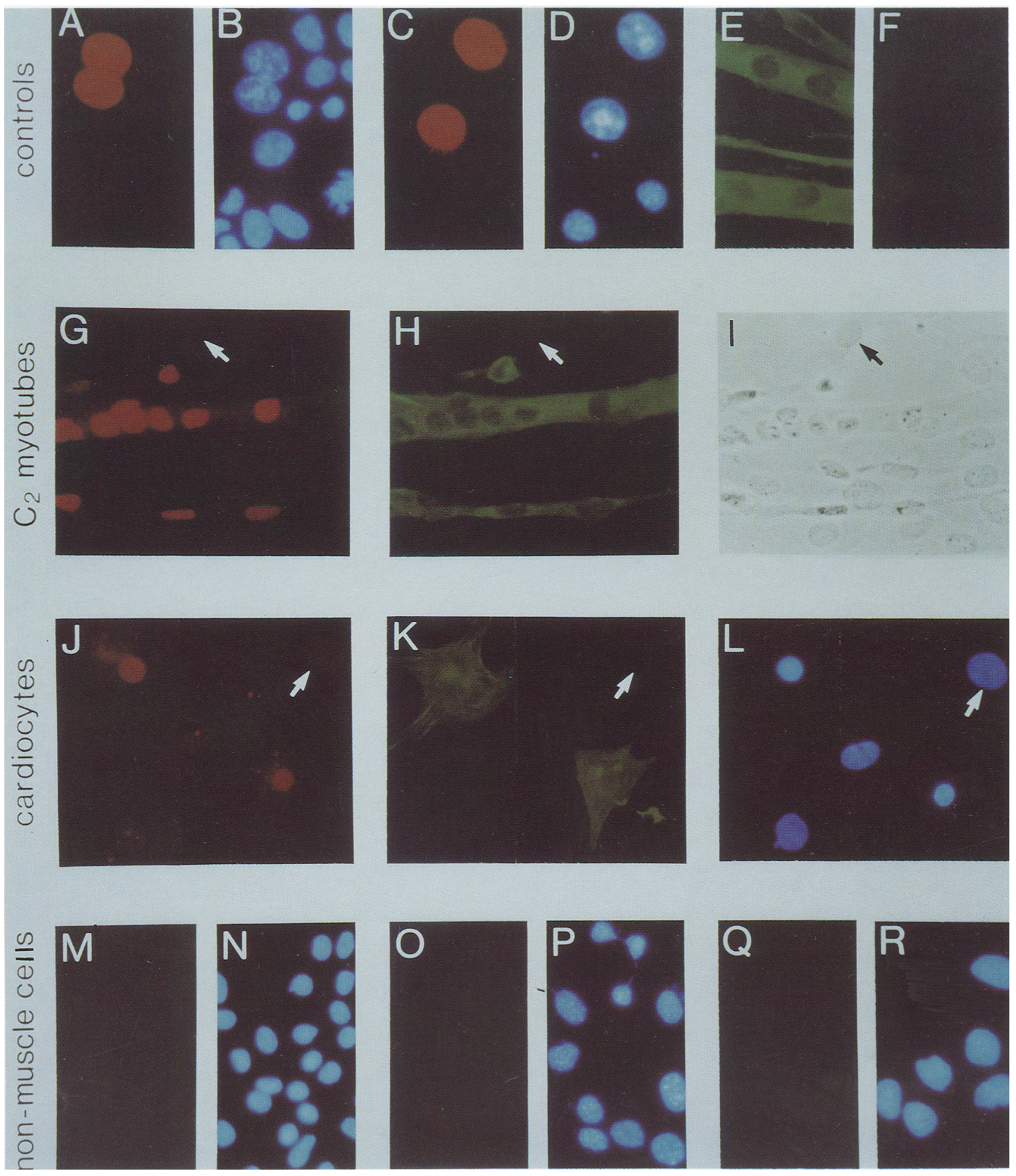

Figure 8. Immunocytofluorescence shows muscle-specific distribution of nuclear MEF2 antigen. COS cells transiently transfected with MEF2 $\{A, B\}$ or aMEF2 $\{C, D)$, and untransfected $C 2 C 12$ myotubes $\{E-I \mid$, primary rat cardiocytes $(J-L)$, and nonmuscle cells, including HeLa $(M, N), \mathrm{NIH}-3 \mathrm{~T} 3(O, P)$, and CV-1 $\{Q, R \mid$, were stained by indirect immunofluorescence for MEF2 with Texas-Red $(A, C, F, G, J, M, O, Q)$, or for striated muscle-type $\mathrm{MHC}$ with fluorescein $(E, H, K)$. All nuclei in the same fields were also stained with Hoechst dye $\|(B, D, L, N, P, R) \mathrm{C} 2 \mathrm{C} 12$ cells were visualized under phase contrast $|I| \|$. Arrows mark examples of undifferentiated $\mathrm{C} 2 \mathrm{C} 12$ myoblast and primary cardiac fibroblast nuclei that neither stain with anti-MEF2 nor anti-MHC antibodies. Anti-MEF2 staining was specifically competed by the MEF2 peptide antigen $(F)$ but not by an unrelated peptide (not shown).

expression of MEF2 cDNA in nonmuscle and undifferentiated myogenic cells, which lack endogenous MEF2 activity, invariably resulted in marked trans-activation of reporter constructs containing different MEF2-binding 


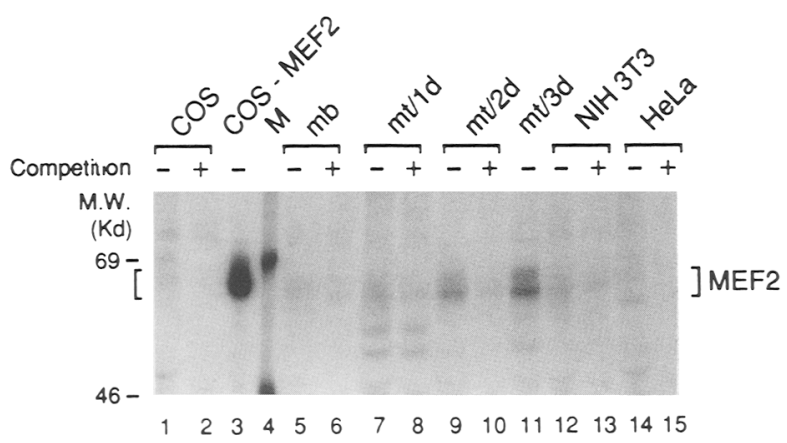

Figure 9. Immunoprecipitation confirms the muscle-specific expression of MEF2 protein during differentiation. Extracts of $\mathrm{C} 2 \mathrm{C} 12$ cells maintained in growth medium, myoblasts $(\mathrm{mb})$, or in differentiation medium, myotubes $(\mathrm{mt})$ for 1,2 , or 3 days $(\mathrm{d})$, as well as of NIH-3T3, HeLa, untransfected COS, and COSMEF2 transfected cells were prepared following a $3 \mathrm{hr}\left[{ }^{35} \mathrm{~S}\right] \mathrm{me}$ thionine labeling and immunoprecipitated with anti- MEF2 antibody either in the absence $\{-\mid$ or presence $(+\mid$ of competing MEF2 peptide antigens. The precipitates were separated in $10 \%$ SDS-PAGE with molecular mass markers $(M)$ and detected by autoradiography. Brackets mark the position of clustered MEF2specific bands at $\sim 67 \mathrm{kD}$.

sites, independent of promoter and cell type. Taken together, these results are definitive evidence that the clones described here encode the MEF2 transcriptional regulators.

\section{MEF2 factors constitute a subgroup within the MADS gene family}

Our results indicate that MEF2 transcriptional activity is not produced by a single protein but, rather, by a group of related proteins. Isoform diversity within this group arises both from expression of a minimum of two genes (but see below) and from alternative RNA splicing. Most striking in all of these isoforms is the 55-amino-acid amino-terminal sequence that is highly homologous to the conserved domain of the MADS gene family. Human SRF and yeast MCMI are known transcriptional activators whose DNA-binding and dimerization domains, like the binding domain of MEF2 here, include the MADS sequence (Norman et al. 1988; Christ and Tye 1991). Moreover, the target DNA sequences for MCMI and SRF are also A/T-rich sites similar to, but distinct from, MEF2 (Hayes et al. 1988; Boxer et al. 1989; Passmore et al. 1989).

In addition to the MADS domain, the MEF2 isoforms also share a conserved 29-residue sequence immediately downstream. This is a MEF2-specific domain that distinguishes these proteins from the other members of the MADS gene family. Rescreening of muscle and brain cDNA libraries has yielded products of at least two other human genes, distinct from those encoding MEF2/ aMEF2 and xMEF2, which contain both MADS and MEF2 domains (J. McDermott and B. Nadal-Ginard, unpubl.). Thus, MEF2 comprises a subfamily of at least four different genes, in agreement with genomic Southern blot analysis showing four or five closely related loci in humans (data not shown). Preliminary data also indicate that alternative splicing expands the isoform diversity for several of these genes. Among the MEF2 proteins characterized here, differences in binding affinity and trans-activation capacity, as well as cell-and tissue-specific patterns of expression, suggest that they have distinct developmental or physiologic functions. The MADS domain shows remarkable evolutionary conservation across all three kindoms. This motif is involved in such diverse cellular functions as growth regulation, mating-type-specific transcription, and cell fate determination. The fact that the MEF2 isoforms are involved in muscle-specific gene transcription, while SRF participates in cell growth regulation, raises the possibility that like the plant MADS genes, MEF2-related factors have a homeotic function during early mammalian development.

\section{Posttranscriptional mechanisms are responsible for cell-specific MEF2 activity}

The strict correlation between the tissue-specificity of MEF2 activity and the presence of MEF2 protein must be reconciled with the ubiquitous presence of MEF2-related RNAs. Immunochemical experiments showed endogenous MEF2 protein to be detectable at high levels only in differentiated skeletal and cardiac muscle nuclei. It is clear, therefore, that in cells devoid of MEF2 activity, MEF2 proteins are either not made or they are selectively degraded. The role of MEF2 RNAs in these cells remains to be determined.

RNA splicing may also participate in the regulation of MEF2 tissue-specificity. Inclusion of the alternatively spliced sequence encoding the SEEEELEL peptide is highly restricted to just those tissues that contain endogenous MEF2 DNA binding and trans-activation. This degree of splicing regulation must be taken as compelling evidence for a role for this peptide in MEF2 activity in skeletal and cardiac muscle and brain. The more straightforward mechanisms would invoke this peptide in DNA-binding or trans-activation; however, we found that the isoforms lacking this sequence bind and activate perfectly well. Whether this domain might confer particular protein stability or be spliced in conjunction with putative alternative $5^{\prime}$-untranlated sequences participating in translational control is unknown. Of note, this sequence is a potential site for casein kinase II phosphorylation.

\section{Pathways distinct from the myogenic bHLH cascade must induce MEF2 in nonskeletal muscle tissues}

The central role of the MyoD family of bHLH factors in the determination of the skeletal muscle lineage is well established (for review, see Rosenthal 1989; Emerson 1990; Olson 1990; Weintraub et al. 1991). Our results and those of others document that MEF2 activity is induced by MyoD and myogenin (Gossett et al. 1989; 
Cseriesi and Olson 1991; Lassar et al. 1991). This induction of MEF2 must contribute significantly to high-level muscle-specific gene transcription triggered by $\mathrm{MyoD}$ endogenously and in many cotransfection experiments reported to date. This finding provides significant insight into the myogenic cascade triggered by these bHLH factors in skeletal muscle. If this cascade proceeds by a single pathway through MEF2, forced expression of MEF2 should be sufficient to induce the muscle phenotype by bypassing the MyoD-related factors. However, although ectopic expression of MEF2 trans-activates responsive reporter genes, it does not produce full myogenic conversion (data not shown). Thus, MEF2 cannot be the sole downstream effector of the skeletal muscle lineage-determining genes. Other transcription factors must be induced in parallel.

Our understanding of the role of the myogenic bHLH proteins in triggering tissue-specific gene expression in skeletal muscle is, in part, difficult to reconcile with the fact that many of the same genes are also expressed in cardiac and, in some cases, smooth muscle, where these bHLH proteins have not been found (Davis et al. 1987; Hopwood et al. 1989; Sassoon et al. 1989; Wright et al. 1989; R.E. Breitbart, unpubl.). Thus, if similar transcription factors regulate expression of the same gene in all three muscle types, these factors must either be regulated independently of the MyoD family or be subject to different modes of regulation in the different muscle types. Although MEF2 is induced by the skeletal muscle bHLH proteins, other lineage-determining pathways must lead to MEF2 expression in nonskeletal muscle tissues.

In this context, the finding that both muscle and brain show high-level expression of the same MEF2 mRNA isoforms strongly suggests that MEF2 also has an important role in neural gene regulation. Striated muscle cells and neurons have certain phenotypic similarities: They share many genes involved in membrane excitability, and both permanently withdraw from the ceil cycle during terminal differentiation. Moreover, bHLH genes play a major role in Drosophila neurogenesis (for review, see Campos-Ortega and Knust 1990); and their mammalian homologs [MASH-1 and -2], thought to be the neural equivalents of the myogenic bHLH proteins, are expressed specifically in the developing central nervous system (Johnson et al. 1990; Lo et al. 1991). Experiments are in progress to determine whether these neuronal bHLH genes trigger MEF2 expression in nerve cells. Whether bHLH or other factors induce the MEF2 genes in cardiac and smooth muscle, as well as nerve, the regulatory sequences of these genes will serve as powerful tools for the dissection of the lineage-determining pathways in these cell types.

\section{MEF2 and SRF-related proteins}

As noted, Pollock and Treisman (1991) recently reported three SRF-related cDNA clones isolated from nonmuscle sources that are alternatively spliced isoforms of the MEF2 factors described here. There is considerable agree- ment between their findings and our own, but salient differences exist in both the apparent tissue-specificity and transcriptional activity of the corresponding proteins. First, Pollock and Treisman detected RSRFC4/ RSRFC9 antigen ubiquitously in DNA-binding complexes, using an antibody directed against the common carboxyl terminus. These findings are inconsistent with the original characterizations of MEF2 activity (Gossett et al. 1989; Cserjesi and Olson 1991), as well as with our own results showing a highly cell-specific distribution of these factors as determined by immunochemical analyses. Furthermore, trans-activation experiments with RSRFC4/RSRFC9, with target sequences similar to, but distinct from, the MEF2 site, failed to demonstrate that they are transcription factors. This contrasts with the results we report for MEF2, aMEF2, and xMEF2. Sequence differences among these isoforms, including the absence of the acidic peptide SEEEELEL from RSRFC4/ RSRFC9 or, if it is not a sequencing discrepancy, the translational reading frameshift producing a different carboxyl terminus, could have important implications for their function. However, we have demonstrated that the a ${ }^{*}$ MEF2 isoform, lacking the SEEEELEL peptide, is a fully active MEF2 site-dependent transcription factor in cotransfection experiments. In addition, the N10-binding site used in the experiments of Pollock and Treisman (1992) mediates this trans-activation as well as the MCK MEF2 site in our hands. Our results confirm the strict tissue-specificity of MEF2 activity and establish that this activity is due, at least in part, to the gene products described here.

\section{Materials and methods}

Cloning and sequencing of MEF2 CDNAs

The initial MEF2 cDNA clone was obtained by screening $1.5 \times 10^{6}$ recombinants from a $\lambda$ GT11 expression library generated from primary human skeletal myocytes from vastus lateralis with a probe containing four concatenated copies of the MEF2 site from the mouse MCK enhancer $(-1081 /-1059)$ (Sternberg et al. 1988; 5'. GATCCTCGCTCTAAAAATAACCCTGTC-3') at specific activity (sp. act.) of $7.8 \times 10^{8} \mathrm{cpm} / \mu \mathrm{g}$. The screening procedures of Singh et al. (1988) were followed with several modifications. The filters were blotted in $1 \times$ binding buffer $[1 \times \mathrm{BB}=20 \mathrm{mM}$ HEPES $(\mathrm{pH} 7.9), 50 \mathrm{mM} \mathrm{KCl}, 0.2 \mathrm{mM}$ EDTA, $1 \mathrm{mM}$ DTT) containing $5 \%$ nonfat milk powder (Carnation). After two washes in $1 \times \mathrm{BB}, 0.25 \%$ milk, the filters were incubated in the same buffer containing $10 \mu \mathrm{g} / \mathrm{ml}$ of poly[d(IC) $/$ poly[d(I-C)], $10 \mu \mathrm{g} / \mathrm{ml}$ of denatured salmon sperm DNA, and the ${ }^{32} \mathrm{P}$-labeled MEF2 probe $\left(1.7 \times 10^{6} \mathrm{cpm} / \mathrm{ml}\right)$ at room temperature for $1 \mathrm{hr}$. The filters were then kept at $4^{\circ} \mathrm{C}$ overnight with gentle agitation, followed by four washes with $0.25 \%$ milk in $1 \times \mathrm{BB}$ at $4^{\circ} \mathrm{C}$ for $25 \mathrm{~min}$, and subjected to autoradiography. One positive clone was purified, and the DNA insert $(2.97 \mathrm{~kb})$ was subcloned and completely sequenced.

For DNA hybridization screening, cardiac ventricle cDNA libraries from human in $\lambda Z A P I I$ (Stratagene, LaJolla, CA) and dog in $\lambda$ gt 10 (Scott et al. 1988) were screened according to Sambrook et al. (1989), by use of the 387-bp MEF2 cDNA fragment (nucleotides $342-728$ ) as the probe labeled to a sp. ac. of $10^{8}-10^{9}$ $\mathrm{cpm} / \mu \mathrm{g}$.

Cloned cDNAs were sequenced with automated instrumen- 
tation (Applied Biosystems, Foster City, CA) by use of a modified dideoxy chain termination method (for review, see Connell et al. 1987). Sequences were verified by multiple runs for both strands. Computer analysis of nucleic acid and protein sequences was performed with the University of Wisconsin Genetics Computer Group Sequence Analysis Software Package (Devereux et al. 1984) and the BLAST Network Service of the National Center for Biotechnology Information (Altschul et al. 1990).

\section{RNA blot analysis}

Poly $\mid \mathrm{A})^{+}$RNAs blots from cultured cells and mouse tissues 15 $\mu \mathrm{g} /$ lane) were prepared according to Sambrook et al. (1989). The human tissue mRNA blot $(2 \mu \mathrm{g} /$ lane) was obtained from Clontech (Palo Alto, CA). Blots were hybridized in $1 \mathrm{M} \mathrm{NaCl}, 50 \mathrm{~mm}$ Tris- $\mathrm{HCl}(\mathrm{pH} 7.5), 1 \%$ SDS, $100 \mu \mathrm{g} / \mathrm{ml}$ of calf thymus DNA, $10 \%$ dextran sulfate, and $50 \%$ formamide with $1 \times 10^{6} \mathrm{cpm} / \mathrm{ml}$ of probe at $42^{\circ} \mathrm{C}$. The probes were those described in the legends to Figures 5 and 6 . The blots were then washed at increasing stringencies up to $0.1 \times \mathrm{SSC} / 0.1 \% \mathrm{SDS}$ at $60^{\circ} \mathrm{C}$. Between probes, blots were completely stripped.

\section{Reverse transcription/polymerase chain reaction} analysis of alternatively spliced RNAs

MEF2 gene-specific single-stranded synthetic oligodeoxynucleotides were used for reverse transcription (RT) (antisense nucleotides 1493-1468 in Fig. 1A) and subsequent polymerase chain reaction (PCR) amplification (sense nucleotide 1222-1242, antisense nucleotides 1443-1417) of total RNAs from various human tissues and cultured cells according to Sambrook et al. (1989). Southern blots of the products were probed with radiolabeled oligodeoxynucelotides hybridizing either to the common (antisense nucleotides 1385-1357) or the exon-specific (antisense nucleotides 1305-1276) sequence, as in Wallace and Miyada (1987). Parallel reactions without reverse transcriptase gave no PCR products.

\section{Immunochemical analyses}

Synthetic peptides corresponding to the partial alternative exons in MEF2 and aMEF2 (Fig. IA), TPHTEEKYKKINEEF(C) and $|C| D Y F E H S P L S E D R$, respectively, were used to raise antibodies against MEF2 and aMEF2 (Harlow and Lane 1988). The specificities of the antisera were demonstrated by EMSA and immunoprecipitation by use of MEF2 and aMEF2 translated in vitro or expressed in transfected COS cells and by indirect immunostaining of transfected COS cells (see Fig. 8A-D). The antiMEF2 antiserum recognized both MEF2 and aMEF2 isoforms, whereas the anti-aMEF2 recognized aMEF2 only.

For indirect immunostaining, cells were fixed in $1 \%$ formaldehyde in phosphate-buffered saline (PBS) for $5 \mathrm{~min}$ at room temperature, incubated with $\mathrm{PBS} / 3 \%$ bovine serum albumin (BSA) $/ 0.1 \% \mathrm{NP}-40$ for $30 \mathrm{~min}$, and then with rabbit anti-MEF2 antiserum diluted $1: 300$ in mouse monoclonal anti-MHC hybridoma supernatant (MF-20; Bader et al. 1982) for $60 \mathrm{~min}$. After a brief wash in $\mathrm{PBS} / 0.1 \%$ NP-40, cells were incubated with a mixture of biotin-coupled donkey anti-rabbit immunoglobulin (Amersham) and FITC-coupled goat anti-mouse IgG (Sigma) for $30 \mathrm{~min}$, then with streptavidin-coupled Texas-Red (Amersham) diluted $1: 500$ in PBS $/ 3 \%$ BSA $/ 0.1 \%$ NP-40 for 30 min. Before mounting in $90 \%$ glycerol, the nuclei were stained with Hoechst 33258 (Sigma, $1 \mu \mathrm{g} / \mathrm{ml}$ ) for $1 \mathrm{~min}$.

For metabolic protein labeling, cells were methionine starved for $2 \mathrm{hr}$ and incubated in $\left[{ }^{35} \mathrm{~S} \mid\right.$ methionine $(50 \mu \mathrm{Ci} / \mathrm{ml})$ for $3 \mathrm{hr}$.
Whole-cell extracts were prepared in $20 \mathrm{mM}$ HEPES-KOH $1 \mathrm{pH}$ $7.81,0.6 \mathrm{M} \mathrm{KCl}, 20 \%$ glycerol, $2 \mathrm{~mm}$ DTT, $1 \mathrm{mM}$ EDTA, and 2 $\mu \mathrm{g} / \mathrm{ml}$ of leupeptin (Kumar and Chambon 1988). ${ }^{35} \mathrm{~S}$-labeled MEF2 was immunoprecipitated (Harlow and Lane 1988) with the following modifications: Extracts with equal TCA-precipitable counts were precleared with $5 \mu$ l of rabbit serum (Sigma) and $50 \mu$ l of protein A-sepharose $11: 1$ in RIPA buffer; Repligen) in $500 \mu$ l of RIPA buffer for $1 \mathrm{hr}$ at $4^{\circ} \mathrm{C}$, and incubated for $2 \mathrm{hr}$ with $50 \mu \mathrm{l}$ of fresh protein A-Sepharose and $10 \mu \mathrm{l}$ of anti-MEF2 antiserum that was preincubated with or without $5 \mu \mathrm{M}$ each peptide antigen for $1 \mathrm{hr}$.

\section{Synthetic oligonucleotides used in EMSA}

All probes and competitor DNAs were double-stranded synthetic oligonucleotides. For each DNA, the nucleotide sequence (one strand, linker sequence shown in parentheses) and coordinates in the respective genes are as follows: MEF2, see above; point mutants of MEF2 (MEF2mt, MEF2mt4, and MEF2mt6; Cserjesi and Olson 1991), see Table $1 ; A / T e m b, 5^{\prime}$-(AGCTT/CGGACCCTGCTCATTTCTATATATA/G)-3' (rat embryonic MHC $-176 /-151$; Bouvagnet et al. 1987); CArG, 5'. (AGCTT)GGGGACCAAATAAGGCAAGGT(G)-3' (human cardiac $\alpha$-actin - 114/-93; Miwa and Kedes 1987); OTF-2, 5' (GATCC) TTCCCAATGATTTGCATGCTCTCAC-3' (immunoglobulin $\kappa$ light chain $-75 /-51$; Scheidereit et al. 1987); MLC2-HF-1, 5'-(GATC) TCCCTGGGGTTAAAAATAACCCCATGAC-3' (rat cardiac MLC-2 -35/-62; Zhu et al. 1991); MCK A/T, 5'-(GATC)GATCGATGCCTGGTTATAATTAACCCAGACAT-3' (mouse MCK - 1200/-1173; Sternberg et al. 1988); cTNT A/T, 5' -(GATC)TCCGACGGGTTTAAAATAGCAAAACTCT-3' (chicken cardiac troponin T -226/-199; Iannello et al. 1991); aMHC A/T-, 5'-(GATC)CCTTTCAGATTAAAAATAACTAAGGTAA- $3^{\prime}$ and $\alpha$ MHC A/T-2, $5^{\prime}-$ - GAT C)GCCCAAGGACTAAAAAAAGGCCCTGGA-3' (rat $\alpha$-MHC $-340 /-313$ and $-228 /-202$, respectively; Mahdavi et al. 1984).

\section{Preparation of nuclear extracts and EMSA}

Nuclear extracts from $\mathrm{C} 2 \mathrm{C} 12$ myoblasts, myotubes, HeLa cells, and rat primary neonatal cardiocytes were prepared as described (Yu and Nadal-Ginard 1989; Thompson et al. 1991), and those from NIH-3T3 cells, 10Tl/ 2 cells, and rat smooth muscle cells (Rothman et al. 1992) were as in Schreiber et al. (1990). The EMSA assays were carried out as in Yu and Nadal-Ginard (1989), with modifications. For EMSA with nuclear extracts, incubations contained 4-7 $\mu \mathrm{g}$ of extract, $0.2 \mathrm{ng}$ of probe, $3-3.5 \mu \mathrm{g}$ of poly[d(I-C)]/poly[d(I-C)], and 100 to $150 \mathrm{ng}$ of single-stranded oligonucleotide as nonspecific DNA competitors. For EMSA with in vitro-translated proteins, incubations contained $1.5 \mu \mathrm{l}$ of translated reticulocyte lysate, $0.2 \mathrm{ng}$ of probe, $0.45 \mu \mathrm{g}$ poly[d(I-C)]/poly[d(I-C)], and $100 \mathrm{ng}$ of single-stranded oligonucleotide. Electrophoresis was carried out on $5 \%$ polyacrylamide gels (acrylamide : bis $=29: 1$ ) at $4^{\circ} \mathrm{C}$. For supershift EMSA, 1 $\mu \mathrm{l}$ of polyclonal antibodies was used as in Brennan and Olson (1990).

\section{Eukaryotic expression vector construction}

For in vitro and in vivo expression of cloned MEF2 isoforms, the cDNA inserts were subcloned into pGEM vectors (Promega Corp., Madison, WI) and pMT2 vector (Kaufman et al. 1989), respectively. To generate MHCemb-CAT and TK-CAT reporter constructs, two copies of various MEF2-binding sites were inserted at -102 of the MHCemb promoter in $\mathrm{pE} 102 \mathrm{CAT}$ 
(Yu and Nadal-Ginard 1989) or at -109 of the HSV TK gene promoter in pTKCAT (Thompson et al. 1991).

\section{Tissue culture and transient expression assays}

Tissue culture, transient transfections, and CAT assays were as described (Yu and Nadal-Ginard 1989; Thompson et al. 1991; Rothman et al. 1992/. Transfections were carried out with $10 \mu \mathrm{g}$ of CAT reporters, $5 \mu \mathrm{g}$ of pMT2-MEF2 or pMT2 vectors, and 3 $\mu \mathrm{g}$ of the internal control pSV- $\beta$-gal.

\section{Acknowledgments}

We are indebted to Drs. Leslie Leinwand and Paul Allen for cDNA libraries; Jay Schneider for RNA blots; Russell Widom, Ami Okada, and Dmitri Krajnc for certain RNAs and nuclear extracts; and Eric Olson for sharing results prior to publication. Marcus Braz, Tom O'Keeffe, Ruth Steinbrich, and Tami Seaman contributed invaluable technical assistance, and Emily Flynn McIntosh prepared the graphics. This work was supported, in part, by grants from the National Institutes of Health and the Muscular Dystrophy Association.

The publication costs of this article were defrayed in part by payment of page charges. This article must therefore be hereby marked "advertisement" in accordance with 18 USC section 1734 solely to indicate this fact.

\section{References}

Altschul, S.F., W. Gish, W. Miller, E.W. Myers, and D.J. Lipman. 1990. Basic local alignment search tool. /. Mol. Biol. 215: 403-410.

Bader, D., T. Masaki, and D.A. Fischman. 1982. Immunochemical analysis of myosin heavy chain during avian myogenesis in vivo and in vitro. J. Cell Biol. 95: 763-770.

Bouvagnet, P.F., E.E. Strehler, G.E. White, M.-A. Strehler-Page, B. Nadal-Ginard, and V. Mahdavi. 1987. Multiple positive and negative 5 ' regulatory elements control the cell-typespecific expression of the embryonic skeletal myosin heavy chain gene. Mol. Cell. Biol. 7: 4377-4389.

Boxer, L.M., R. Prywes, R.G. Roeder, and L. Kedes. 1989. The sarcomeric actin CArG-binding factor is indistinguishable from the c-fos serum response factor. Mol. Cell. Biol. 9: 515522.

Braun, T., E. Tannich, G. Buschhausen-Denker, and H.H. Arnold. 1989. Promoter upstream elements of the chicken cardiac myosin light-chain 2-A gene interact with trans-acting regulatory factors for muscle-specific transcription. Mol. Cell. Biol. 9: 2513-2525.

Brennan, T.J. and E.N. Olson. 1990. Myogenin resides in the nucleus and acquires high affinity for a conserved enhancer element on heterodimerization. Genes \& Dev. 4: 582-595.

Buskin, J.N. and S.D. Hauschka. 1989. Identification of a myocyte nuclear factor that binds to the muscle-specific enhancer of the muscle creatine kinase gene. Mol. Cell. Biol. 9: 2627-2640.

Campos-Ortega, I.A. and E. Knust. 1990. Genetics of early neurogenesis in Drosophila melanogaster. Annu. Rev. Genet. 24: 387-407.

Christ, C. and B.-K. Tye. 1991. Functional domains of the yeast transcription/replication factor MCM1. Genes \& Dev. 5: 751-763.

Coen, E.S. and E.M. Meyerowitz. 1991. The war of the whorls: Genetic interaction controlling flower development. Nature 353: $31-37$.
Connell, C., S. Fung, S. Heiner, J. Bridgham, V. Chakerian, E. Heron, B. Jones, S. Menchen, W. Mordan, M. Raff, M. Recknor, L. Smith, J. Springer, S. Woo, and M. Hunkapiller. 1987 Automated DNA sequence analysis. BioTechniques 5: $342-$ 348.

Courey, A.T. and R. Tjian. 1988. Analysis of SPI in vivo reveals multiple transcriptional domains, including a novel glutamine-rich activation motif. Cell 55: 887-898.

Courey, A.J., D.A. Holtzman, S.P. Jackson, and R. Tjian. 1989. Synergistic activation by the glutamine-rich domains of human transcription factor spl. Cell 59: 827-836.

Cseriesi, P. and E.N. Olson. 1991. Myogenin induces the myocytes-specific enhancer binding factor MEF- 2 independently of other muscle-specific gene products. Mol. Cell. Biol. 11: $4854-4862$.

Davis, R.L., H. Weintraub, and A.B. Lassar. 1987. Expression of a single transfected cDNA converts fibroblasts to myoblasts. Cell 51: 987-1000.

Devereux, I., P. Haeberli, and O. Smithies. 1984. A comprehensive set of sequence analysis programs for the VAX. Nucleic Acids Res. 12: 387-395.

Emerson, C.P. 1990. Myogenesis and developmental control genes. Curr. Opin. Cell Biol. 2: 1065-1075.

Emerson, C., D. Fischman, B. Nadal-Ginard, and M.A.D. Siddiqui. 1986. Molecular biology of muscle development. Alan R. Liss, New York.

Gossett, L.A., D.J. Kelvin, E.A. Stemberg, and E.N. Olson. 1989 A new myocyte-specific enhancer-binding factor that recognizes a conserved element associated with multiple musclespecific genes. Mol. Cell. Biol. 9: 5022-5033.

Harlow, E. and D. Lane. 1988. Antibodies: A laboratory manual. Cold Spring Harbor Laboratory, Cold Spring Harbor, New York.

Hayes, T.E., P. Sengupta, and B.H. Cochran. 1988. The human $c$-fos serum response factor and the yeast factors GRM/ PRTF have related DNA-binding specificities. Genes \& Dev. 2: 1713-1722.

Hopwood, N., A. Pluck, and J. Gurdon. 1989. MyoD expression in the forming somites is an early response to mesoderm induction in Xenopus embryos. EMBO I. 8: 3409-3417.

Horlick, R.A., G.M. Hobson, J.H. Patterson, M.T. Mitchell, and P.A. Benfield. 1990. Brain and muscle creatine kinase genes contain common TA-rich recognition protein-binding regulatory elements. Mol. Cell. Biol. 10: $4826-4836$.

Iannello, R.C., J.H. Mar, and C.P. Ordahl. 1991. Characterization of a promoter element required for transcription in myocardial cells. J. Biol. Chem. 266: 3309-3316.

Jelinek, W.R. and C.W. Schmid. 1982. Repetitive sequences in eukaryotic DNA and their expression. Annu. Rev. Biochem. 51: 813-844.

Johnson, J.E., S.J. Birren, and D.J. Anderson. 1990. Two rat homologues of Drosophila achaete-scute specifically expressed in neuronal precursors. Nature 346: 858-861.

Kaufman, R.J., M.V. Davies, V.K. Pathak, and J.W.B. Hershey. 1989. The phosphorylation state of eukaryotic initiation factor 2 alters translational efficiency of specific mRNAs. Mol. Cell. Biol. 9: 946-958.

Kumar, V. and P. Chambon. 1988. The estrogen receptor binds tightly to its responsive element as a ligand-induced homodimer. Cell 55: 145-156.

Lassar, A.B., R.L. Davis, W.E. Wright, T. Kadesch, C. Murre, A. Voronova, D. Baltimore, and H. Weintraub. 1991. Functional activity of myogenic HLH proteins requires hetero-oligomerization with E12/E47-like proteins in vivo. Cell 66: 305315 .

Lo, L.C., J.E. Johnson, C.W. Wuenschell, T. Saito, and D.J. 
Anderson. 1991 Mammalian achaete-scute homolog $\mathrm{I}$ is transiently expressed by spatially restricted subsets of early neuroepithelial and neural crest cells. Genes \& Dev. 5: 1524-1537.

Mahdavi, V., A.P. Chambers, and B. Nadal-Ginard. 1984. Car$\operatorname{diac} \alpha$-and $\beta$-myosin heavy chain genes are organized in tandem. Proc. Natl. Acad. Sci. 81: 2626-2630.

Mar, J.H. and C.P. Ordahl. 1990. M-CAT binding factor, a novel trans-acting factor governing muscle-specific transcription. Mol. Cell. Biol. 10: 4271-4283.

McKnight, S.J. and R. Kingsbury. 1982. Transcriptional control signals of a eukaryotic protein-coding gene. Science 217: $316-324$.

Mermod, N., E.A. O'Neill, J.J. Kelly, and R. Tjian. 1989. The Proline-rich transcriptional activator of CTF/NF-1 is distinct from the replication and DNA-binding domain. Cell 58: 741-753.

Miller, J.B. 1990. Myogenic programs of mouse muscle cell lines: Expression of myosin heavy chain isoforms, myoDl, and myogenin. J. Cell Biol. 111: 1149-1159.

Miwa, T. and L. Kedes. 1987. Duplicated CArG boxes domains have positive and mutually dependent regulatory role in expression of the human $\alpha$-cardiac actin gene. Mol. Cell. Biol. 7: 2803-2813.

Mueller, P.R. and B. Wold. 1989. In vivo footprinting of a muscle specific enhancer by ligation mediated PCR. Science 246: 780-785.

Muscat, G.E.O., T.A. Gustafson, and D.L. Kedes. 1988. A common factor regulates skeletal and cardiac $\alpha$-actin gene transcription in muscle. Mol. Cell. Biol. 8: 4120-4133.

Norman, C., M. Runswick, R. Pollock, and R. Treisman. 1988. Isolation and properties of cDNA clones encoding SRF, a transcription factor that binds to the $\mathrm{c}$-fos serum response element. Cell 55: 989-1003.

Olson, E.N. 1990. MyoD Family: A paradigm for development? Genes \& Dev. 4: 1454-1461

Passmore, S., R. Elble, and B.-K. Tye. 1989. A protein involved in minichromosome maintenance in yeast binds a transcriptional enhancer conserved in eukaryotes. Genes \& Dev. 3: 921-935.

Peterson, C.A., H. Gordon, Z.W. Hall, B.M. Paterson, and H.M. Blau. 1990. Negative control of the helix-loop-helix family of myogenic regulators in the NFB mutant. Cell 62: 493-502.

Pollock, R. and R. Treisman. 1991. Human SRF-related proteins: DNA-binding properties and potential regulatory targets. Genes \& Dev. 5: 2327-2341.

Rosenthal, N. 1989. Muscle cell differentiation. Curr. Opin. Cell Biol. 1: 1094-1101.

Rothman, A., T.J. Kulik, M.B. Taubman, C.B. Bradford, C.W.J. Smith, and B. Nadal-Ginard. 1992. Development and characterization of a cloned rat pulmonary arterial smooth muscle cell line which maintains differentiated properties through multiple subcultures. Circulation (in press).

Sambrook, J., E.F. Fritsch, and T. Maniatis. 1989. Molecular cloning: A laboratory manual, 2nd ed. Cold Spring Harbor Laboratory Press, Cold Spring Harbor, New York.

Sassoon, D., G. Lyons, W.E. Wright, V. Lin, A. Lassar, H. Weintraub, and M. Buckingham. 1989. Expression of two myogenic regulatory factors myogenin and myoDl during mouse embryogenesis. Nature 341: 303-307.

Scheidereit, C., A. Heguy, and R.G. Roeder. 1987. Identification and purification of a human lymphoid-specific octamerbinding protein (OTF-2) that activates transcription of an immunoglobulin promoter in vitro. Cell 51: 783-793.

Schreiber, E., K. Harshman, I. Kemler, U. Malipiero, W. Schaffner, and A. Fontana. 1990. Astrocytes and glioblas- toma cells express novel octamer DNA-binding proteins distinct form the ubiquitous oct-1 and B cell type oct- 2 proteins. Nucleic Acids Res. 18: 5495-5503.

Schwarz-Sommer, Z., P. Huijser, W. Nacken, H. Saedler, and H. Sommer. 1990. Genetic control of flower development by homeotic genes in antirrhinum majus. Science 250: 931936.

Scott, B., H. Simmerman, J. Collins, B. Nadal-Ginard, and L. Jones. 1988. Complete amino acid sequence of canine cardiac calsequestrin deduced by cDNA cloning. I. Biol. Chem 263: 8958-8964

Singh, H., J.H. LeBowitz, A.S. Baldwin Jr. and P.A. Sharp. 1988. Molecular cloning of an enhancer binding protein: Isolation by screening of an expression library with a recognition site DNA. Cell 52: 415-423.

Stemberg, E.A., G. Spizz, W.M. Perry, D. Vizard, T. Weil, and E.N. Olson. 1988. Identification of upstream and intragenic regulatory elements that confer cell-type-restricted and differentiation-specific expression on the muscle creatin kinase gene. Mol. Cell. Biol. 8: 2896-2909.

Thompson, W.R., B. Nadal-Ginard, and V. Mahdavi. 1991. A myoDl-independent muscle-specific enhancer controls the expression of the $\beta$-myosin heavy chain gene in skeletal and cardiac muscle cells. J. Bio. Chem. 266: 22678-22688.

Wallace, R.B. and C.G. Miyada. 1987. Oligonucleotide probes for the screening of recombinant DNA libraries. Guide to molecular cloning techniques. Methods Enzymol. 152: 432442 .

Walsh, K. and P. Schimmel. 1987. Two nuclear factors compete for the skeletal muscle actin promoter. I. Biol. Chem. 262: 9429-9432.

Weintraub, H., S.J. Tapscott, R.L. Davis, M.J. Thayer, M.K. Adam, A.B. Lassar, and A.D. Miller. 1989. Activation of muscle-specific genes in pigment, nerve, fat, liver, and fibroblast cell lines by forced expression of myoD. Proc. Natl. Acad. Sci. 86: 5434-5438.

Weintraub, H., R. Davis, S. Tapscott, M. Thayer, M. Krause, R. Benezta, T.K. Blackwell, D. Turner, R. Rupp, S. Hollenberg, Y. Zhuang, and A. Lassar. 1991. The myoD gene family: Nodal point during specification of the muscle cell lineage. Science 251: 761-766.

Wentworth, B.M., M. Donoghue, J.C. Engert, E.B. Berglund, and N. Rosenthal. 1991. Paired myoD-binding sites regulate myosin light chain gene expression. Proc. Natl. Acad. Sci. 88: 1242-1246.

Wright, W.E., D.A. Sassoon, and V.K. Lin. 1989. Myogenin, a factor regulating myogenesis, has a domain homologous to myoD. Cell 56: 607-617.

Yu, Y.-T. and B. Nadal-Ginard. 1989. Interaction of nuclear proteins with a positive cis-acting element of rat embryonic myosin heavy-chain promoter: Identification of a new transcriptional factor. Mol. Cell. Biol. 9: 1839-1849.

Zhu, H., A.V. Garcia, R.S. Ross, S.M. Evans, and K.R. Chien. 1991. A conserved 28-base-pair element (HF-1) in the rat cardiac myosin light-chain-2 gene confers cardiac-specific and $\alpha$-adrenergic-inducible expression in cultured neonatal rat myocardial cells. Mol. Cell. Biol. 11: 2273-2281. 


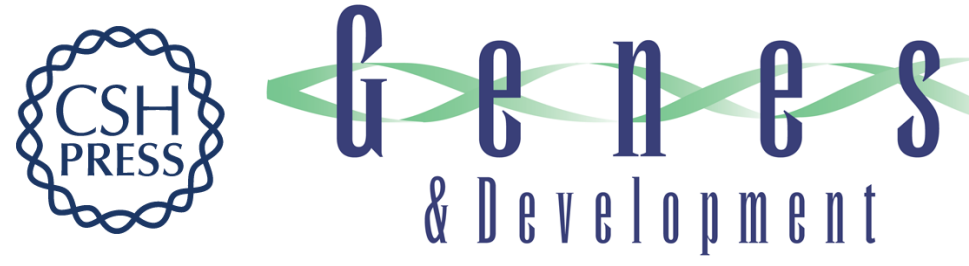

\section{Human myocyte-specific enhancer factor 2 comprises a group of tissue-restricted MADS box transcription factors.}

Y T Yu, R E Breitbart, L B Smoot, et al.

Genes Dev. 1992, 6:

Access the most recent version at doi:10.1101/gad.6.9.1783

References This article cites 58 articles, 34 of which can be accessed free at: http://genesdev.cshlp.org/content/6/9/1783.full.html\#ref-list-1

License

Email Alerting Service

Receive free email alerts when new articles cite this article - sign up in the box at the top right corner of the article or click here.

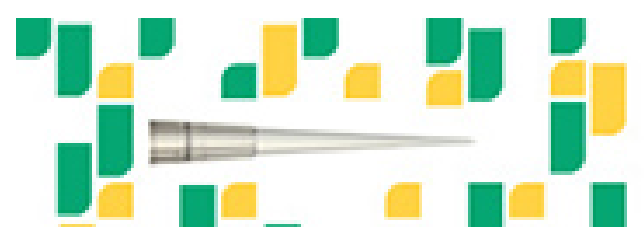

Focused on your science. 